\title{
The effect of heat treatments on pure and potassium doped drawn tungsten wires: Part II - Fracture properties
}

\author{
Vladica Nikolića , Johann Riesch ${ }^{b}$, Manuel J. Pfeifenberger ${ }^{a}$, Reinhard Pippan ${ }^{a}$ \\ ${ }^{a}$ Erich Schmid Institute of Materials Science of the Austrian Academy of Sciences, Leoben, Austria \\ ${ }^{\mathrm{b}}$ Max-Planck-Institut für Plasmaphysik, Garching, Germany
}

\section{Keywords}

Tungsten wires, potassium doping, fracture toughness, SEM fractographs, annealing, recrystallization

\begin{abstract}
Advanced tungsten fibre-reinforced composites $\left(\mathrm{W}_{\mathrm{f}} \mathrm{W}\right)$, showing pseudo ductile behaviour even at room temperature, are a promising option for future fusion reactors as the intrinsic brittleness of tungsten can be mitigated effectively. The drawn tungsten wires used as reinforcements are the key component of the composites, thus their mechanical properties and thermal stability define the allowed operation / fabrication temperature of the composite material itself. In this work, the room temperature fracture behaviour of the pure and potassium doped tungsten wires was investigated, focusing on the evolution of the fracture micromechanisms in respect to annealing. Single-edge-notched specimens were used, with the crack growth direction perpendicular to the drawing axis of the wire. The occurrence of either a brittle or a ductile response in the as-received state of both materials is a strong indication that the ductile-to-brittle transition temperature is about room temperature. Pure, annealed tungsten wire experiences a tremendous deterioration of the fracture toughness with a very prominent transition of the failure mode. The observed embrittlement by annealing can be related to the loss of the fibrous, elongated microstructure. In contrast to this, the results of the annealed, doped wire demonstrate that the microstructural stability and preservation of the initial, beneficial grain structure is directly reflected in the crack resistance of the material. Predominately ductile behaviour, with characteristic knife-edge necking, is seen even after annealing at $1600^{\circ} \mathrm{C}$.
\end{abstract}




\section{Introduction}

The progress of the next generation of fusion reactors is strongly associated with the development of advanced high heat flux and plasma-facing materials, capable of enduring the challenging environment imposed by extreme operating conditions $[1,2]$. An extensive research regarding the first wall and divertor materials was conducted in recent years [3] leading to the choice of tungsten based materials as the most prominent candidates for these reactor parts [4,5]. Besides many advantageous properties of this refractory metal, the challenges associated with the use of tungsten (W) in high-temperature applications are its typically brittle nature and relatively high ductile to brittle transition temperature [6]. Further operational embrittlement is expected as a result of tremendous amount of neutron irradiation [7] and/or by annealing through recrystallization and grain growth $[8,9]$. Thus, one of the main goals in the development of the novel tungsten based material options is overcoming the problem of brittleness.

The broad range of conducted studies on the ductility and toughness enhancement of tungsten at lower temperatures led to the three main strategies being alloying (e.g. with $\operatorname{Re}[10,11]$ or $\operatorname{Ir}[12]$ ), nanostructuring [13,14] and synthesizing composite materials. The third approach is a very promising option, in particular when thinking of tungsten fibre-reinforced tungsten composites $\left(\mathrm{W}_{\mathrm{f}} / \mathrm{W}\right)$ [15], where brittleness is mitigated by utilizing extrinsic toughening mechanisms [16]. $\mathrm{W}_{\mathrm{f}} / \mathrm{W}$ composites consist of commercially available drawn tungsten wires which are embedded in a tungsten matrix, either by a chemical deposition process [17] or by powder metallurgy [18]. Thus, key components which determine the structural integrity of these advanced plasma facing composites are the tungsten wires used as fibres, which sets the requirement of their exceptional properties and brings an interest in studying them.

Drawn tungsten wire was of great importance in the past century as it was originally developed for the illumination industry and used as the main filament element for light bulbs [19]. Initial studies were mostly focused on the production process and creep resistance at very high temperatures which led to the discovery of the exceptional influence of doping of tungsten by a small amount of potassium (K) [20]. In such a way, the embrittlement of pure tungsten as a result of recrystallization, grain growth and thermal fatigue, which directly influenced lifetime performance of the lamps, was successfully mitigated. The advantageous effect of doping was correlated to the formation of $\mathrm{K}$ bubbles at the grain boundaries, which supress the secondary recrystallization to higher temperatures and keep the initial, beneficial microstructure for a longer timespan [21]. The research in the following 
years was mostly dedicated to the optimization of the manufacturing process and high temperature stability of the microstructure.

When used as reinforcement element in the composite materials, the performance of the tungsten wire and in particular its crack resistance properties at moderate temperatures are of fundamental importance. Investigations dealing with the fracture behaviour of $\mathrm{W}$ wire conducted over the past decades, focused on a wide range of different topics such as the typical failure modes occurring during the drawing process [22], complex mechanisms of lamp filaments deterioration [23], analyses of the wire splitting as a result of bending, stretching or coiling [24,25], just to name a few. Furthermore, several studies were addressing the influence of the microstructure on the occurrence of different fracture modes [26,27], as well as discussing the effect of grain structure of recrystallized wires [28].

However, despite the existing significant body of research on tungsten wires, there are still some open questions and gaps in the scientific knowledge, where a deeper microscopic understanding of the important properties is needed. This is particularly true for the crack resistance of the wire, where more comprehensive information regarding the fracture mechanisms as well as correlation to the underlying microstructure is of the utmost importance. This holds true for both the as-received as well as the annealed state of the wire.

Determination of the relationship between the microstructural features and the resulting properties is one of the main goals of the performed work, as the variations in the grain structure are strongly reflected in the materials fracture properties. This contribution is the second part of the study conducted on pure and potassium doped wires. In the first part, the question of recrystallization phenomena and microstructural stability was addressed [29], through detailed analyses of the evolution of various aspects of the microstructure with annealing temperature. The main scope of this part of the study is the room temperature fracture toughness assessment of tungsten wires and the investigation of the evolution of the fracture mechanisms in respect to different heat treatments.

\section{Materials and experimental methods}

The investigated materials are commercially available drawn pure (W) and potassium doped (K-W, 60ppm) tungsten wires, with a diameter of $150 \mu \mathrm{m}$, which were provided by the OSRAM GmbH, Schwabmünchen. The typical production steps of tungsten-based materials involve a powder metallurgical process of 
sintering and swaging, while the final, small dimension of the wire is obtained by series of subsequent drawing steps.

In order to study the effect of heat treatments and annealing phenomena on the resulting fracture behaviour, the experiments were performed on both as-received and annealed samples. Based on the microstructural characterization conducted in the first part of the publication, two annealing temperatures were chosen for this study: $1300{ }^{\circ} \mathrm{C}$ and $1600{ }^{\circ} \mathrm{C}$. The results indicate that the pure tungsten wire recrystallizes when annealed for $1 \mathrm{~h}$ at $1300^{\circ} \mathrm{C}$, while the highest temperature of $1600{ }^{\circ} \mathrm{C}$ induces substantial grain growth. In contrast, the elongated microstructure of the doped wire remains mostly preserved throughout the heat treatments. In such a way, selected temperatures enable investigating the relation between the microstructural evolution and the embrittlement by annealing and/or ductility conservation. The oxidation of the wires during heat treatments was prevented by using a tungsten based vacuum furnace (Leybold Heraeus PD 1000). The annealing was done at a pressure $<10^{-5}$ mbar with the holding time of $1 \mathrm{~h}$ with subsequent furnace cooling. All the samples are assumed to have identical chemical composition as they were cut from the same two spools of wires. Thus, the influence of the composition on the resulting properties can be excluded.

Single-edge notched tension (SENT) specimens were used for studying the damage tolerance of the investigated materials. Hence, the fracture experiments were conducted in one principal testing direction with the crack growth directions perpendicular to the drawing axis of the wires. The notches were introduced by a femtosecond (fs) laser (Origami $10 \mathrm{XP}$, Onefive $\mathrm{GmbH}$ ), which is attached to the Auriga FIB/SEM workstation, enabling a precise positioning of the laser cuts. It has a pulse duration of about 500 fs and a focused spot size diameter of about $25 \mu \mathrm{m}$. Further details on the laser system can be found elsewhere [30]. The processing of the notches was performed under vacuum conditions with a fluence of $0.6 \mathrm{~J} / \mathrm{cm}^{2}$ and a pulse repetition rate of $100 \mathrm{kHz}$. The laser beam is guided across the sample surface by a galvanometer scanner. It was scanned repeatedly 14 times with a speed of $1 \mathrm{~mm} / \mathrm{s}$ along a line, sufficient to cover the whole diameter of a wire. Hence, the time required for the processing of a single notch is below 4 seconds making laser cutting a very fast and therefore advantageous notch fabrication technique. Due to the ultrashort pulse duration the heat influence on the material is negligible in the ideal case [31]. The typical sample length of the wire was about $20 \mathrm{~mm}$ with the notch depth being about one third of the wire diameter. Furthermore, in order to investigate the influence of a nearly atomically-sharp flaw in a material, some of the as-received samples also contained a pre-crack like notch introduced by a FIB workstation (FIB, Leo 1540, Zeiss). A crack-like structure, with the length of $50 \mu \mathrm{m}$, was milled in the centre of the laser notch using an ion current of $5 \mathrm{nA}$ for $30 \mathrm{~min}$. 
An example of a top view of a laser notch (perpendicular to the drawing axis) as well as the position of the FIB cut can be seen in Figure 1a.

Fracture mechanical experiments were performed on a small scale tensile testing machine provided from Kammrath and Weiss, with a maximum load capacity of 200 $\mathrm{N}$. All the tests were displacement controlled at the rate of $1 \mu \mathrm{m} / \mathrm{s}$ and were done at room temperature in air. Number of tested samples containing only a laser notch for the as-received and all annealed state were six and three, respectively. An additional four tested samples, in the as-received state, had a FIB pre-crack as well. This was the same for both pure and K-doped wires. Thus, the reported fracture toughness values are statistical averages, with the indicated error bars being the standard deviation of the average values. During the experiments, the load-displacement curves were recorded which were used in evaluating the critical stress intensity factor K.K as a measure of fracture toughness of the SENT specimen subjected to tensile loading conditions was evaluated according to [32]:

$$
K=\sigma * \sqrt{\pi * a} * f\left(\frac{a}{D}\right)
$$

where $\sigma$ is the applied stress of the round bar given by $\sigma=4 F / \pi D^{2}, F$ is the force, $D$ the diameter of the wire and $a$ the length of the transverse semi-elliptical surface crack. A minimal length of a crack is taken for all the calculations, which is determined from fracture surfaces by a straight line parallel to the end of a notch, as shown in Figure $1 \mathrm{~b}$. In each test, the $\mathrm{K}$ is calculated with the maximum recorded load. The dimensionless geometry factor $f\left(\frac{a}{D}\right)$ can be obtained numerically by the finite element method [33] and for a straight-fronted edge crack is given as:

$$
f\left(\frac{a}{D}\right)=1.4408-3.6364\left(\frac{a}{D}\right)+19.3500\left(\frac{a}{D}\right)^{2}-34.7849\left(\frac{a}{D}\right)^{3}+36.8446\left(\frac{a}{D}\right)^{4}
$$

The fracture surfaces of the samples were investigated with a scanning electron microscope (SEM, LEO Gemini 1525) equipped with a field emission gun and the evolution of the morphology of fracture surfaces was obtained in respect to different annealing conditions and material states. Additionally, a backscatter electron (BSE) detector was used to examine the initial microstructure across the longitudinal and cross sections of the as-received and heat treated wires. The preparation of samples suitable for these analyses was conducted by embedding the wire pieces in hard resin, followed by standard polishing steps resulting in the necessary smooth surfaces. 

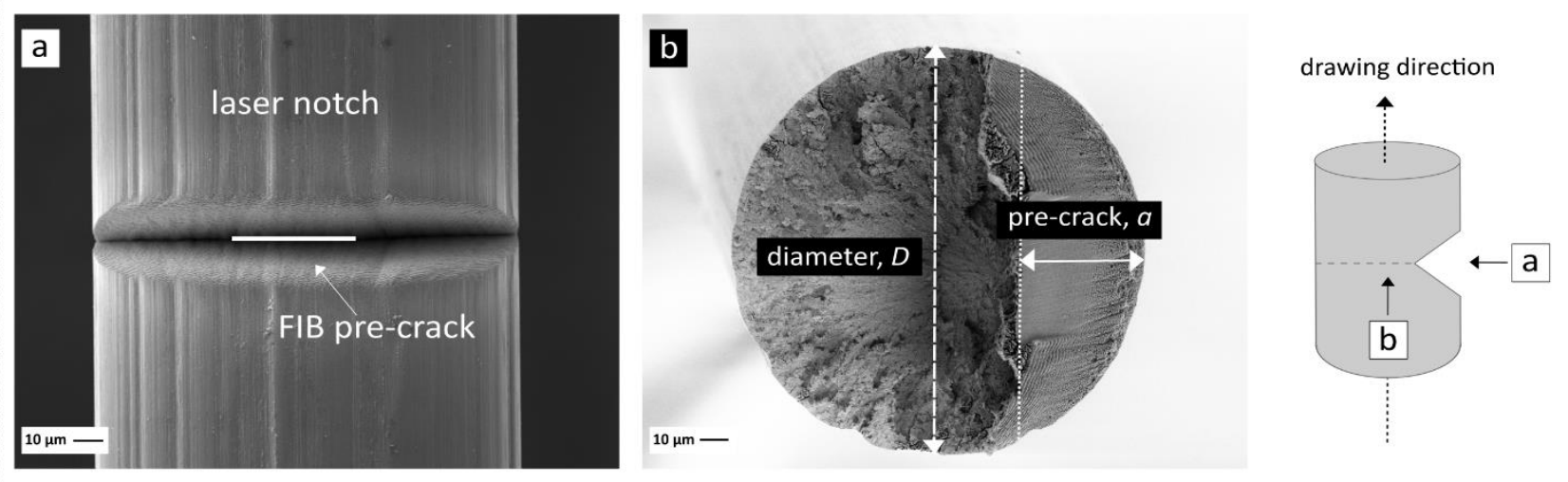

Figure 1. Scanning electron micrographs of a) a top view of a laser notch with designated position of a FIB cut and b) an exemplary fracture surface showing how a minimal length of a pre-crack was measured. The schematic drawing on the right illustrates a characteristic SENT specimen with indicated viewing directions.

\section{Results and discussion}

\subsection{Microstructure}

In order to determine the role of the underlying microstructure in the resulting fracture process and failure mode, it is very important to investigate the grain structure of the studied materials prior to fracture experiments. BSE images can be used as a suitable representation of the microstructure as the contrast of the image, related to different crystallographic orientations, gives a very good impression of the grain size and shape. An overview of the pure and potassium doped material is seen in two principal viewing directions: longitudinal section - plane parallel to the drawing axis (Figure 2a) and cross section - plane perpendicular to the drawing axis (Figure $2 b)$. Furthermore, comparison between as-received, $1300{ }^{\circ} \mathrm{C} / 1 \mathrm{~h}$ and $1600{ }^{\circ} \mathrm{C} / 1 \mathrm{~h}$ states enable studying the effect of heat treatments and annealing phenomena on the resulting fracture behaviour.

The initial appearance of the both materials is very similar, which is directly influenced by the severe plastic deformation imposed on the wire during the drawing process. In such a way, a unique microstructure is obtained consisting of thin, fibrous 
grains elongated along the axial direction, as clearly seen in the longitudinal sections. The BSE images of the cross sections reveal uniformly distributed grains twisted around each other and thus forming a characteristic pattern known as grain curling or the so called Van Gogh sky structures [34]. This unique microstructural feature is related to the tendency of grains to deform by plane strain elongation [35] and in such a way they become shaped like ribbons curled around the wire axis. Such an appearance is typically seen in heavily deformed tungsten wire and has been reported by other researchers $[36,37]$.

The grain structure and related microstructural features of the two investigated materials appear rather different after annealing at successively increasing temperatures. In the case of the pure, undoped W wire substantial microstructural modifications occur. As seen in Figure 2a, the characteristic elongated structure is severely influenced already after annealing at $1300^{\circ} \mathrm{C}$, experiencing increase in the grain size in both horizontal and vertical directions. Significant grain growth leads to the complete loss of fibrous appearance, where the microstructure of the final state consists of large, quasi-symmetric, globular $\mu \mathrm{m}$ sized grains. Furthermore, cross sectional examinations reveal the complete disappearance of curling structures, the tremendous grain growth and formation of large, equiaxed shaped grains.

In contrast to annealing properties of pure tungsten, the overall elongated microstructure of the K-doped W wire is preserved even for the highest annealing temperatures, indicating a very pronounced thermal stability of the material. Minor structural changes occurring in the range of the investigated temperatures are related to the small amount of lateral boundary movement leading to an increase of grain width in the longitudinal direction. The effect of heat treatments observed in the plane perpendicular to the drawing direction, is seen through rounding of the grains and their slight increase in size. Furthermore, the disappearance of the grain curling is seen as well.

A comprehensive microstructural characterization and the more in-depth investigation of the influence of annealing on the pure and potassium-doped tungsten wires was already performed. Thus, for all the details regarding quantification of changes of the grain shape and size, analyses of the grain boundaries, evolution of the developed texture and influence of heat treatments on hardness, the reader is referred to [29]. 


\section{a) longitudinal section}
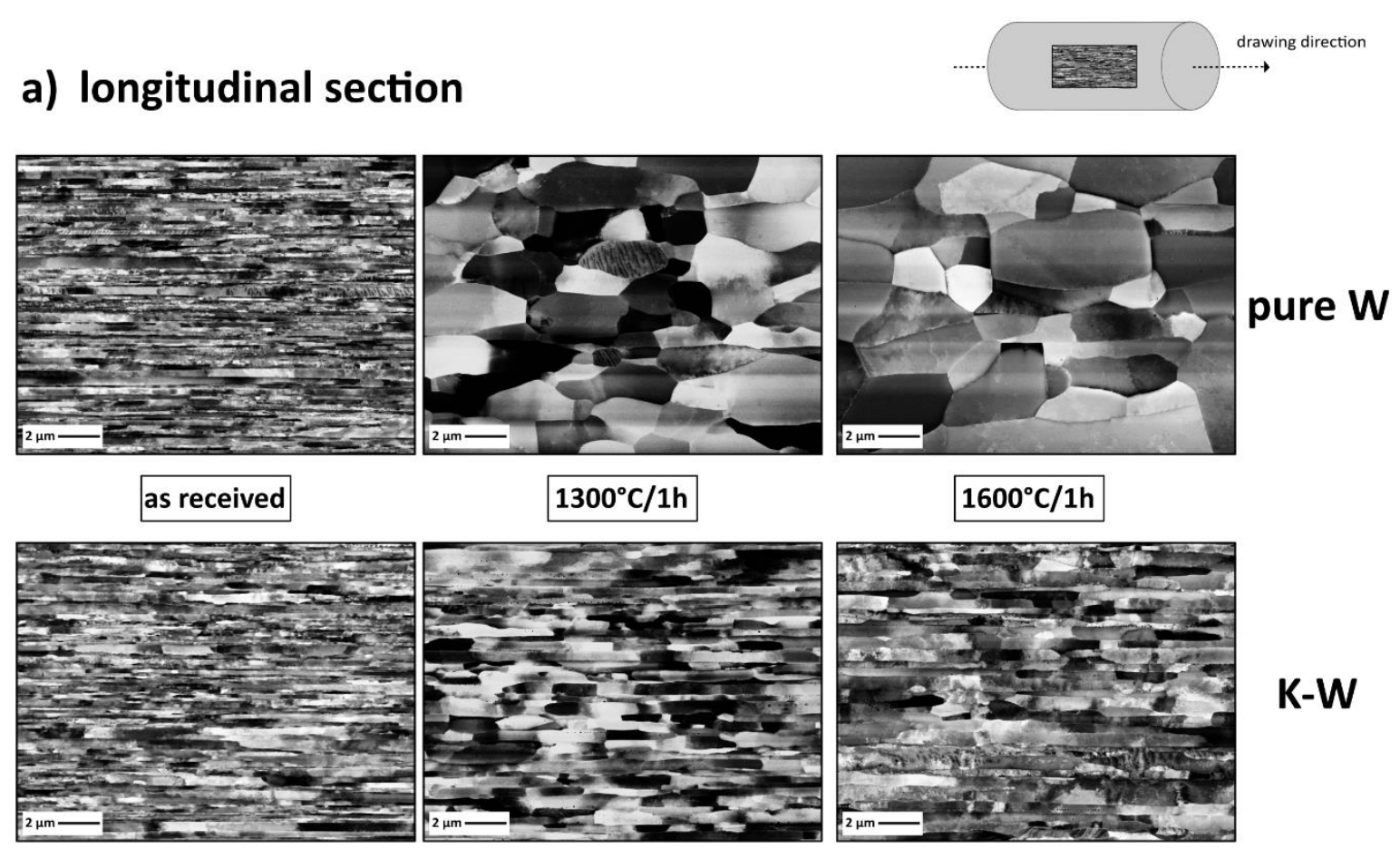

\section{b) cross section}
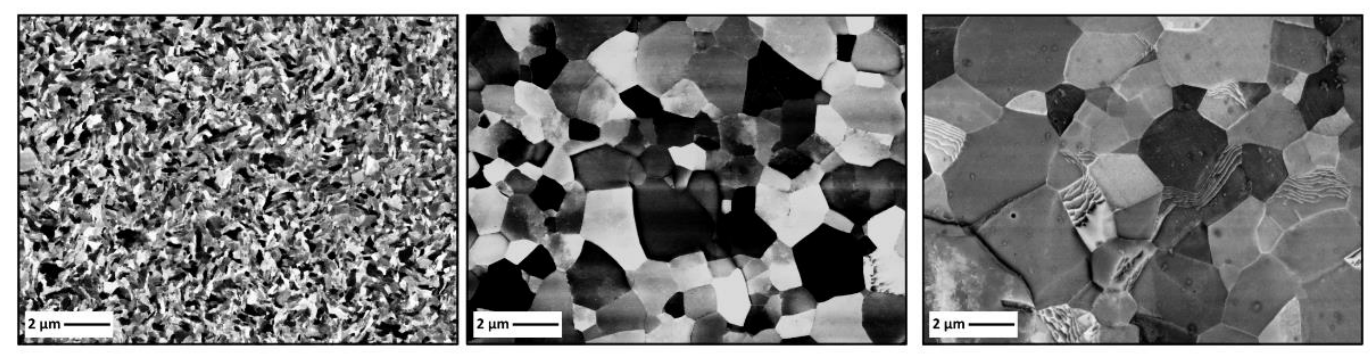

K-W
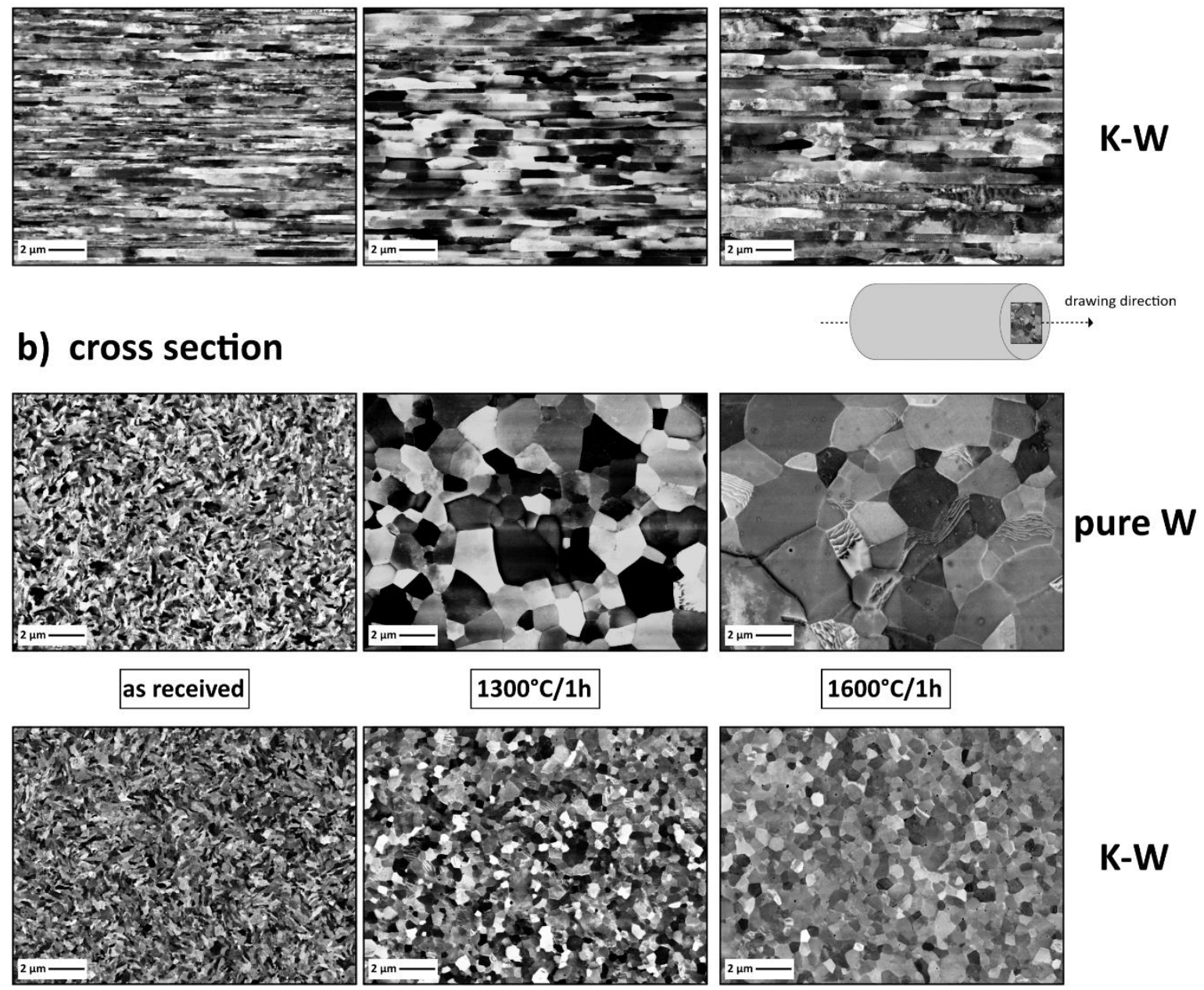

Figure 2. Scanning electron micrographs, taken in BSE mode, of the pure and K-doped tungsten wires in the as-received and annealed states $\left(1300^{\circ} \mathrm{C}\right.$ and $1600{ }^{\circ} \mathrm{C}$ for $\left.1 \mathrm{~h}\right)$. The images are taken in the central area across a) longitudinal sections and b) cross-sections. The schematic drawings show the principle direction of deformation as well as the position of the typical scanning areas in respect to the drawing direction. 


\subsection{Fracture toughness}

\subsubsection{As-drawn wires}

Typical load-displacement curves obtained in a fracture experiment on wires in the as-received state are shown for pure and potassium doped tungsten wires in Figure $3 \mathrm{a}$ and Figure $3 \mathrm{~b}$, respectively. A comparison is made between two distinct cases of material's response in a test, namely ductile and brittle failure mode, which occured at the ratio of about $50-50 \%$ of tested samples. In both examples specimens show nearly pure linear elastic loading at the beginning. After a maxium load is reached, a brittle sample fails catastrophically without showing any signs of plastic behaviour with the force abruptly dropping to zero. In contrast to this, a ductile sample sustains a higher maximum load and shows a certain non-linearity in a test record, where the force decreases steadily before a final failure occurs. This is higlighted in the magnified part of the load displacement curve of a pure W (Figure 3a) and similar trends can be be observed for both type of wires.

The critical fracture toughness $\mathrm{K}$ was calculated from the maximum obtained load in an experiment and based on the results of six tested samples, for each type of a material, a mean value of fracture toughness is derived. The measured values for pure and K-doped tungsten are $(33.4 \pm 6.4) \mathrm{MPa} \cdot \mathrm{m}^{1 / 2}$ and $(31.9 \pm 7.2) \mathrm{MPa} \cdot \mathrm{m}^{1 / 2}$, respectively. A rather high standard deviation is related to a scatter of $K$ data which is associated with the occurence of either a brittle or a ductile fracture mode. In the case of a pure tungsten wire, measured fracture toughness is in the range from 25.9 $\mathrm{MPa} \cdot \mathrm{m}^{1 / 2}$ (the lowest obtained value of a brittle appearance) to $43.3 \mathrm{MPa} \cdot \mathrm{m}^{1 / 2}$ (the highest obtained value of a ductile appearance). The results of doped wires show a similar variation of $\mathrm{K}$ going from about $22.7 \mathrm{MPa} \cdot \mathrm{m}^{1 / 2}$ to $44.5 \mathrm{MPa} \cdot \mathrm{m}^{1 / 2}$. The existence of a scatter of measured fracture toughness data under the same testing conditions strongly indicates that the testing temperature (in this case room temperature) is in the range where a transition from a brittle to a ductile failure mode takes place. Similar scatter of $\mathrm{K}$ data in a fracture experiment at room temperature was also observed for heavily rolled ultrafine grained tungsten foil [14].

Furthermore, in Figure 3 an overview of characteristic fracture morphologies can be seen. The displayed fractographs represent either a brittle or a ductile material behaviour related to low or high values of fracture toughness. In both cases, a crack immediately deflects along the longitudinal direction of the wire, followed by either a brittle, transcrystalline cleavage or a ductile, knife-edge failure mode accompanied 
with a pronoucne necking. However, an in-depth fractographic investigation will be presented in the following chapters.

\section{a) pure $\mathbf{W}$}
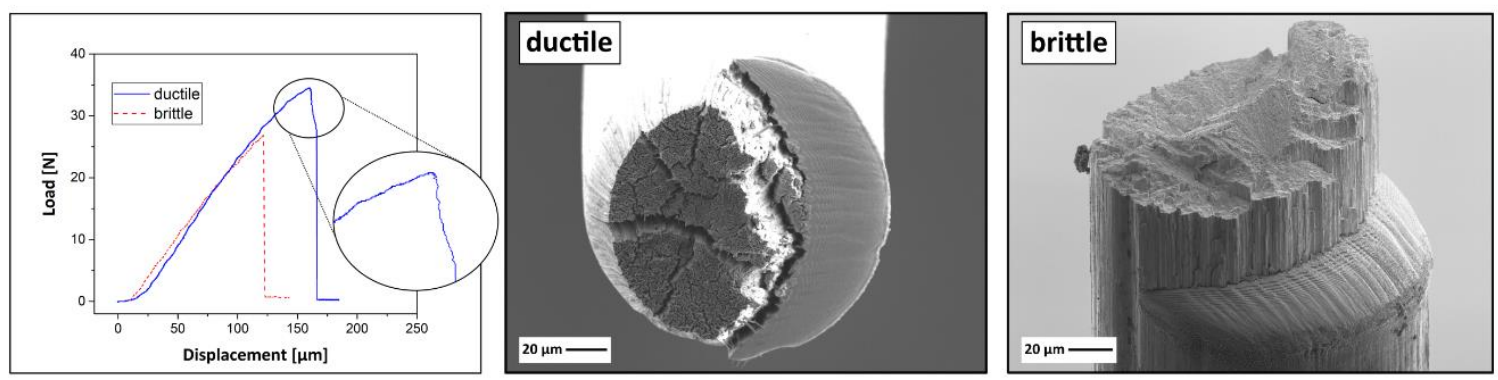

\section{b) $\mathrm{K}$ doped $\mathrm{W}$}
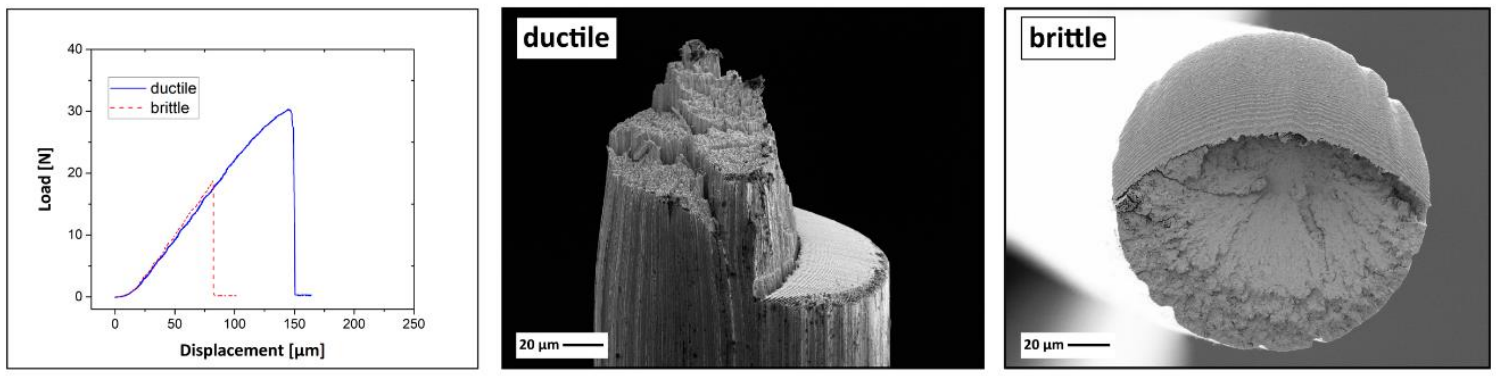

Figure 3. The results of room temperature fracture experiments performed on a) pure tungsten and b) K-doped tungsten wires in the as-received state. The exemplary load-displacement curves and corresponding fractographs indicate the occurrence of both brittle and ductile materials behaviour in a test.

The evaluation of the fracture toughness of pre-cracked wire samples, as a critical value of the stress intensity factor for this material subjected to tensile, mode I loading conditions can be used as a suitable method of measuring failure resistance of such a material. However, following critical remarks implicate an underestimation of the determined fracture toughness values and therefore they need to be discussed:

- The accuracy and/or discrepancy of the results is to some extent influenced by the measurement of the crack length $a$. The shape of the transverse crack in a cylindrical specimen under tension is the key parameter in numerical solutions of dimensionless geometrical factor $f$ occurring in equation 1. Generally speaking, $f$ is dependent on three parameters: the crack depth, the crack aspect ratio and the position of the 
considered point at the crack front [33]. Performing different finite element calculations on the basis of geometrical model of a crack having a different shape (the straight-fronted, semi-elliptical or semi-circular) gives several expressions of $f$ where one, two or all three of aforementioned parameters play a role. In the case of a crack with a straight front, oneparameter K-solutions are obtained i.e. the expression of the dimensionless geometrical factor depends only on the relative crack depth $\frac{a}{D}[33,38]$. K values determined within this study were based on the one-parameter expression approximating a curved laser produced notch to a straight one, defined by a central region of a crack front. Determined values of fracture toughness are underestimated as the minimal crack length $a_{\min }$ was used in the calculations i.e. a longer measured crack length would yield a higher value of $K$.

- Further underestimation of $\mathrm{K}$ comes from a strong deflection of the crack i.e. a deviation of the crack path from its designated mode I propagation direction and thus approaching the direction of the wire axis. As a result, a mixed mode stress state is produced and therefore, the calculated values cannot be considered as a pure mode I fracture toughness. If a crack path and the fracture process would follow the initial plane of the pre-crack, the resulting $\mathrm{K}_{\mathrm{Ic}}$ would be even higher than the reported values. Therefore, the obtained results should be regarded as a lower bound value for the real mode I fracture toughness.

- Determination of the stress intensity factor in the framework of linear elastic fracture mechanics (LEFM) implies a plastic zone significantly smaller than the crack length, the ligament width and specimen thickness. In the regime of increased ductility, as can be seen in some of the tested samples, an elastic plastic evaluation of the fracture toughness would be more suitable. In this case, both the elastic part of the J-integral and the plastic part of the J-integral have to be taken into account. For calculation of $\mathrm{K}$ the later part has not been included, hence the calculated critical stress intensity values can only be considered as a lower limit.

Taking into account all of these considerations, the determined fracture toughness can be treated as an underestimated value. Despite some inaccuracies, in particular in the measurement of the crack length, the same procedure was followed for all of the tested samples. Therefore, when making a comparison between the investigated materials and different annealing conditions, the measured crack resistance can be used as a suitable apparent fracture toughness value. 


\subsubsection{Annealed wires}

Typical load-displacement curves acquired from fracture experiments performed on annealed wires are shown for pure and $\mathrm{K}$ doped $\mathrm{W}$ wires in Figure $4 \mathrm{a}$ and Figure $4 \mathrm{~b}$, respectively. In this case a comparison is made between samples heat treated at $1300^{\circ} \mathrm{C}$ and $1600^{\circ} \mathrm{C}$ for $1 \mathrm{~h}$, where a substantial difference of the two investigated materials can be seen. For both annealing temperatures pure $W$ wires show a typical brittle behaviour in the load-displacement curves with purely linear elastic loading and an abrupt decrease of force. In addition, it is evident that the maximum attained load before a failure is significantly lower than in the case of the as-received wire. In contrast to these observations, a non-linearity of the testing curves can be seen for doped wires, which is comparable to the ductile response of the as-received samples. Regardless of some decrease of the maximum load, even after annealing at the highest temperature of $1600{ }^{\circ} \mathrm{C}$, the wire seems to preserve its good properties.

The measurements of fracture toughness of wires annealed at $1300{ }^{\circ} \mathrm{C}$ yield values of $(9.7 \pm 1.7) \mathrm{MPa} \cdot \mathrm{m}^{1 / 2}$ and $(25.1 \pm 1.9) \mathrm{MPa} \cdot \mathrm{m}^{1 / 2}$ for pure and $\mathrm{K}$-doped tungsten, respectively. The pronounce drop of $\mathrm{K}$, in particular in the case of pure $\mathrm{W}$, is further enhanced for the samples heat treated at $1600^{\circ} \mathrm{C}$. In this case, measured fracture toughness is only $(7.6 \pm 1.1) \mathrm{MPa} \cdot \mathrm{m}^{1 / 2}$ for pure and $(22.6 \pm 3.1) \mathrm{MPa} \cdot \mathrm{m}^{1 / 2}$ for K-doped wire. Such a distinctive difference of the two examined materials is also clearly reflected in the fractographic images. The doped wire fails predominately in a ductile, knife-edge failure manner having a characteristic crack deflection, while for the pure tungsten a planar crack propagation is observed with a typical brittle, mixed mode. Comprehensive evaluation of the failure process and the low fracture resistance will be given by examination of fracture surfaces in chapter 3.3. 


\section{a) pure $\mathbf{W}$}
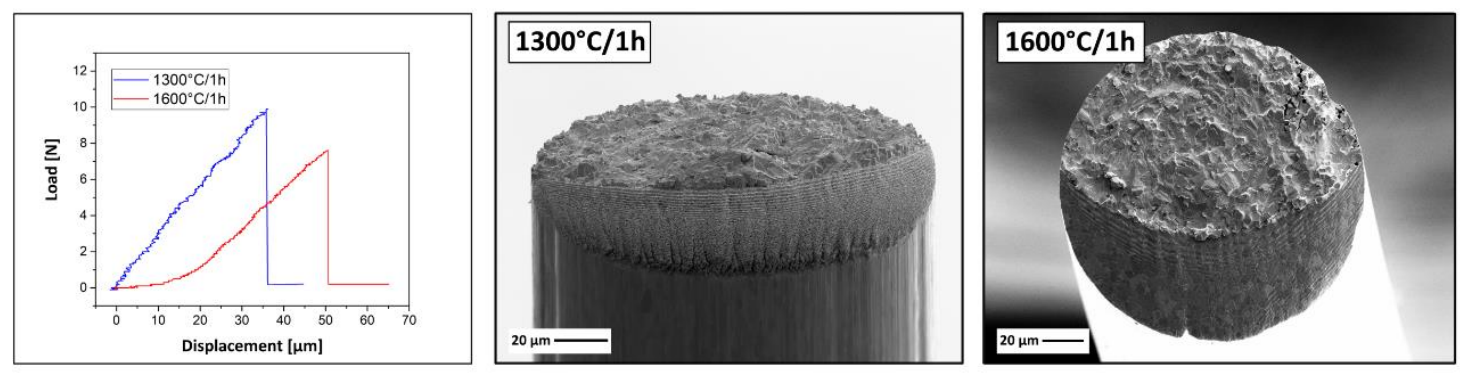

\section{b) $\mathrm{K}$ doped $\mathrm{W}$}
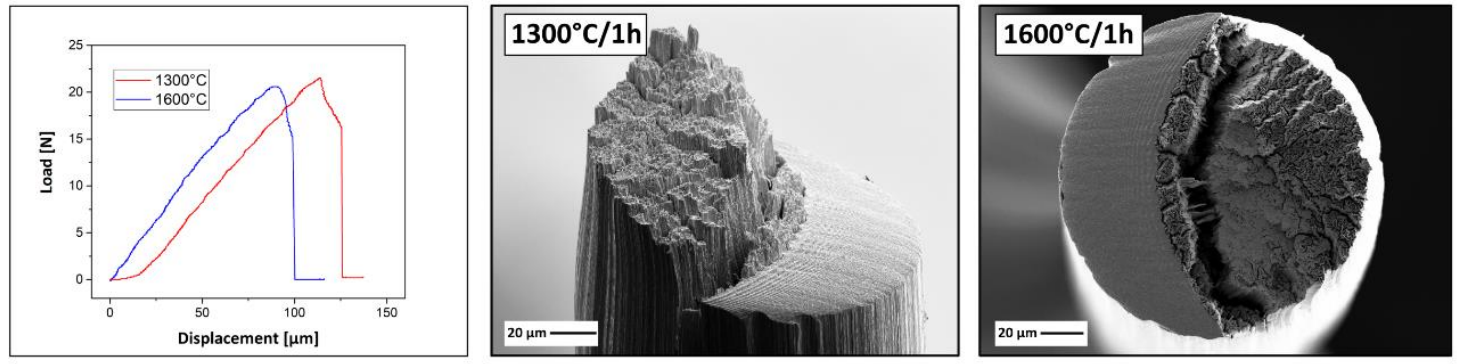

Figure 4. The results of room temperature fracture experiments performed on a) pure tungsten and b) K-doped tungsten wires in two annealed states: $1300^{\circ} \mathrm{C} / 1 \mathrm{~h}$ and $1600{ }^{\circ} \mathrm{C} / 1 \mathrm{~h}$. The exemplary loaddisplacement curves and corresponding fractographs indicate the influence of different heat treatments on the resulting fracture properties.

\subsubsection{Influence of a pre-crack}

An essential aspect of the determination of fracture toughness is the availability of a sharp notch. In terms of conventional notching methods, such as a fatigue precracking, the case of tungsten is somewhat specific due to its typically brittle nature. The selection of the femtosecond laser processed notches is quite advantageous as the root radius yields between 5 and $20 \mathrm{~nm}$ [39], allowing fracture testing also for nanostructured tungsten alloys. A very strong influence of notch root radii on the measured fracture toughness was demonstrated, showing that blunter notches lead to an overestimation of the $\mathrm{K}$ values. Another beneficial characteristic is that fs-laser processing has no influence on the microstructure as it was shown for cold rolled tungsten foils [30]. Sharpening of the conventionally processed notches additionally by a FIB showed a very strong influence on the measured toughness values of the ultrafine grain tungsten foils. A higher $\mathrm{K}_{\mathrm{q}}$ was obtained for samples having a notch introduced only by electrical discharge machining [40] in comparison to lower 
fracture toughness values measured for samples having a sharper pre-crack made subsequently by a diamond wire, razor blade and FIB [41]. The absence of a nearly atomically-sharp worst-case flaw in the material produced by a FIB would lead to an enhancement of the stress level ahead of the tip, resulting in higher apparent toughness values. Furthermore, a link between the sharpness of a notch and resulting fracture behaviour was shown for cold drawn steel wires [42]. Samples having sharp notches presented a microscopically brittle behaviour (higher stress triaxiality), in contrast to ductile fracture process occurring in specimens with blunt notches.

In order to elucidate whether a similar notch effect takes place also for wires, an additional set of as-received samples was investigated, where beside the fs-laser notch, a sharp pre-crack was introduced by means of a FIB. An overview of all the obtained results from both type of materials, where the fracture toughness $K$ is plotted against performed heat treatments, is given in Figure 5 with the associated values shown in Table 1. As already discussed, pure tungsten shows a strong reduction in toughness with an increase of annealing temperature, with the effect being significantly milder in the case of the doped wires. Samples containing a FIB cut are compared against the fs-laser processed samples behaving in a ductile (Fig. $5 a$ ) or a brittle (Fig. 5b) manner. As-received samples with a sharp FIB pre-crack yield mean values of fracture toughness of $(24.3 \pm 1.6) \mathrm{MPa} \cdot \mathrm{m}^{1 / 2}$ and $(22.6 \pm 4.3)$ $\mathrm{MPa} \cdot \mathrm{m}^{1 / 2}$ for pure and K-doped tungsten, respectively. When compared to the averaged fracture toughness of fs-laser processed samples fracturing in a ductile mode, a difference of about $15 \mathrm{MPa} \cdot \mathrm{m}^{1 / 2}$ is observed. However, it is very important to point out that all of the FIB samples failed in exclusively brittle manner with a pronounced $90^{\circ}$ crack deflection followed by a transcrystalline cleavage. Thus, a comparison made in Figure $5 \mathrm{~b}$ is more appropriate when discussing the notch effect. Similar $\mathrm{K}$ values indicate that sharpening of the notch does not lead to the change in a failure mode, which is in this case also dominated by a strong crack deflection at the initial stage of the fracture process. The reasons for the occurence of only a brittle behaviour and cleavage in all of the FIB samples are not obvious and will be further investigated and addressed in the following publication. 
a)

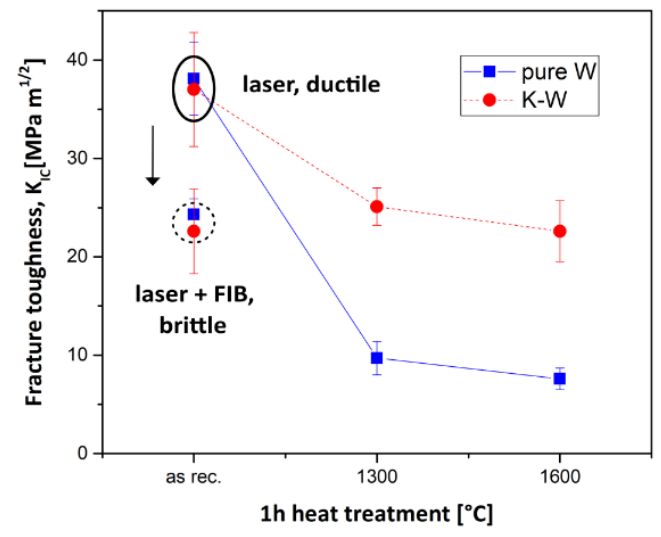

b)

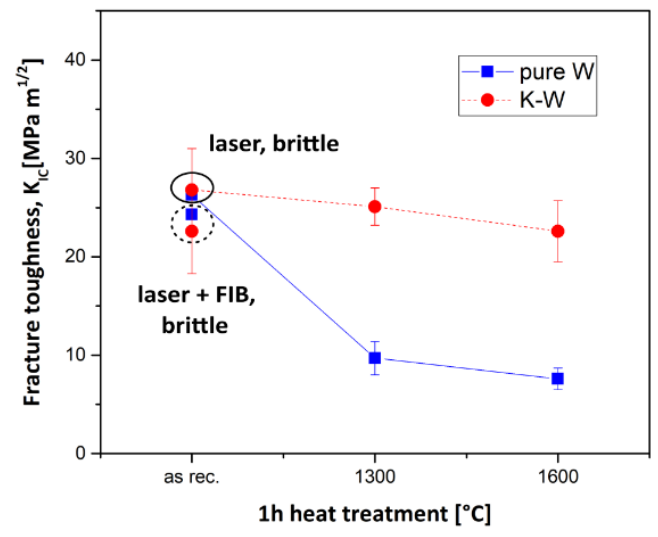

Figure 5. Fracture toughness of pure and K-doped tungsten wires as a function of annealing temperature. The influence of different notch fabrication methods is investigated for the as-received materials, where a comparison is made between FIB samples and laser samples behaving in either a) a ductile or b) a brittle manner.

Table 1. Overview of the fracture toughness results of a pure and K-doped tungsten wire. Comparison is made between different notch techniques, material behaviour as well as annealing conditions of the samples (as-received, $1300{ }^{\circ} \mathrm{C} / 1 \mathrm{~h}$ and $1600{ }^{\circ} \mathrm{C} / 1 \mathrm{~h}$ state of the wire). The majority of the results represents an estimated lower limit of fracture toughness, which is indicated with a "greater than" sign. The bolded results outline a real mode I fracture toughness.

\section{Material state, notch technique $\quad$ Fracture toughness $\left[\mathrm{MPa} \cdot \mathrm{m}^{1 / 2}\right.$ ]}

\begin{tabular}{ccc}
\cline { 2 - 3 } & Pure W & K-doped W \\
\hline as received, laser, mean value & $>33.4 \pm 6.4$ & $>31.9 \pm 7.2$ \\
\hline as received, laser, ductile & $>38.1 \pm 3.7$ & $>37.0 \pm 5.8$ \\
\hline as received, laser, brittle & $>26.3 \pm 0.5$ & $>26.8 \pm 4.2$ \\
\hline as received, laser + FIB, brittle & $>24.3 \pm 1.6$ & $>22.6 \pm 4.3$ \\
\hline $1300^{\circ} \mathrm{C} / 1 \mathrm{~h}$, laser & $\mathbf{9 . 7} \pm \mathbf{1 . 7}$ & $>25.1 \pm 1.9$ \\
$1600^{\circ} \mathrm{C} / 1 \mathrm{~h}$, laser & $\mathbf{7 . 6 \pm 1 . 1}$ & $>22.6 \pm 3.1$
\end{tabular}




\subsection{Fractography}

\subsubsection{As drawn wires}

Fractographic analyses of the failed samples are an essential part in studying fracture behaviour of a material, in particular when it comes to establishing a relationship between the underlying microstructure and the characteristics of the fracture process. As outlined in previous chapter, as-received wires behave in different ways at RT, corresponding to lower or higher values of fracture toughness. Typical fracture morphologies are shown in Figure 6 and Figure 7, where detailed fractographic investigations are performed for brittle and ductile failure mode, respectively.

A unique feature occurring in all of the as-received samples, regardless of the type of failure mode, is a pronounced crack deflection (Figure 6a and Figure 7a). Such a deviation from an anticipated, mode I crack path occurs at the beginning of the fracture event and results in propagation along the drawing direction of the wire for a certain length, before a final fracture surface is formed. This distinct fracture feature occurs as a consequence of the elongated microstructure of heavily drawn wires and is a strong indication of a very prominent anisotropy in fracture toughness. It is implied that the crack growth resistance is significantly higher perpendicular to the aligned grains than parallel to them; consequently, crack deviates upon loading at an angle of about $90^{\circ}$ in relation to the initial fracture plane and follows a path along a weaker crack growth direction. A magnified view of this $90^{\circ}$ propagation step reveals this aligned, fibrous appearance of the microstructure with grains elongated along the drawing direction. So, it is energetically more favourable for a crack to propagate parallel to the wire axis generating longitudinal splitting by separation of individual grains at their weak grain boundaries than to propagate radially in pure mode I direction by breaking the grains. Such a strong anisotropy induced by microstructural orientation and appearing during fracture can also be seen in other materials, for example in the case of cold drawn steel wires $[32,42]$.

The fractographic analyses of a sample behaving brittle (Figure 6 ) reveals that the predominant micromechanisms of the final fracture process is cleavage. Given example is of a pure $\mathrm{W}$ wire, where magnified fracture features are seen in the side (Fig. 6a) and top view (Fig. 6b) of the wire. After the initial deflection of the crack, a mode II fracture appears at the interface between the grains and the resulting final fracture surface is inclined in respect to the initial laser notch plane. The origin of the transgranular cleavage is situated in the central area of the wire with the crack propagating radially and forming characteristic river patterns. Besides this, small 
colonies of grains with a cleavage surface roughly perpendicular to the wire axis can be seen (bottom magnified fractograph in Figure 6a), which are related to the $\{110\}$ cleavage plane and arise as a consequence of the $\langle 110\rangle$ fibre texture. The occurrence of the $\{110\}$ cleavage in heavily-drawn wires can be considered a special case imposed by the extremely fibrous nature of the structure and a very sharp texture [27]. Moreover, the dominating brittle appearance is characterized by a missing necking of the wire diameter and a small amount of longitudinal micro-crack formation, located at the edge region (bottom magnified fractograph in Figure 6b).
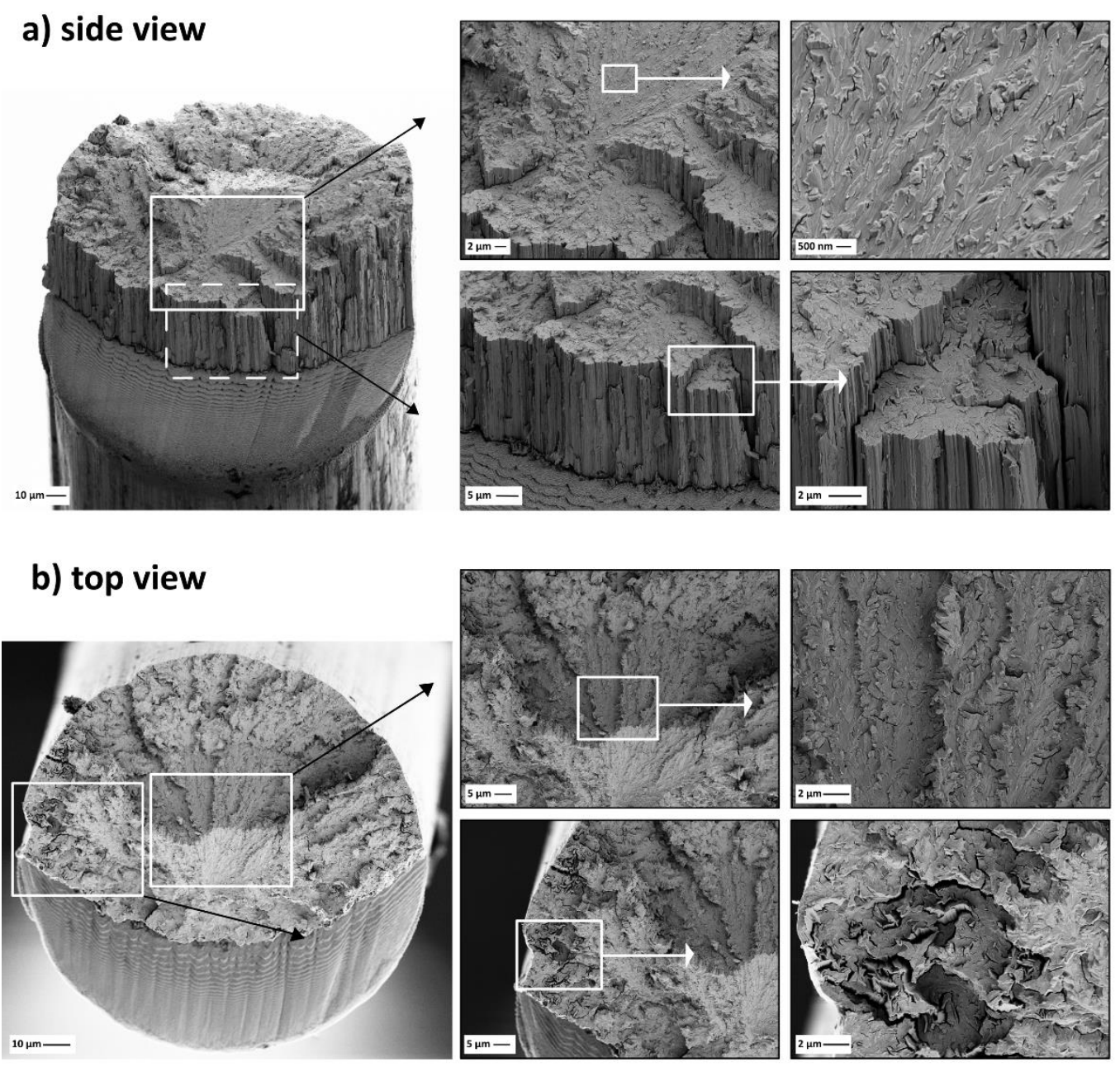

Figure 6. Scanning electron micrographs of a pure tungsten wire showing a typical brittle, cleavage dominated fracture behaviour. Fracture surfaces are studied in a) a side view and b) a top view of the wire in respect to a laser notch. The most characteristic features of the fracture process are shown in the magnified images. 
The fracture morphology demonstrating a ductile behaviour of the as-received wires, seen in Figure 7, is shown for the K-doped material. This fracture appearance is typically designated as ductile, knife-edge failure mode and after crack deflection it is characterized by distinct necking of the entire wire, followed by longitudinal cracking and necking of individual grains to almost $100 \%$ reduction in area (bottom magnified fractograph in Figure 7a). Significantly higher amount of plastic deformation, when compared to the sample behaving in a brittle manner, is seen through pronounced necking of the wire which is in a good correlation with the obtained load-displacement curve. A direct influence of the curled grains, observed in the cross sections of the untested wire (Figure $2 b$ ), can be seen from the fractographs taken in the top view (Figure $7 \mathrm{~b}$ ), revealing that the fracture surface consists of intertwined, convoluted ribbons. Knife-edge necking of individual grains, similar to the knife-edge fracture observed in a $<110>$ tungsten single crystal, occurs within these ribbons and results from their intrinsic plane strain elongation [27], which is a consequence of the $\{110\}$ fibre texture.

Further peculiar features of the fracture surfaces are deep crevices running in the radial direction of the wire and are often referred to as delaminations. Closer inspection of the magnified fractographs reveals that between large delaminations, smaller ones can be observed as well, which alongside with individual grain necking lead to the fracture surface appearing as a network of lines. Delaminations occur by a decohesion of the grains along their longitudinal grain boundaries and thus propagate along the wire drawing direction. It is a process that proceeds necking of the individual grains, indicating that these boundaries are too weak to support tensile stresses generated during necking, which is also an indication that the interfibre fracture toughness is significantly lower than the strength of the grains themselves [27]. As a result, the occurrence of delaminations permits the individual grains to act as bundled, individual wires which will be manifested through their aforementioned reduction in area. Furthermore, the existence of the grain boundary delaminations is closely related to the reduction in the stress triaxiality which leads to the increased crack resistance. The formation of these longitudinal cracks along the weak boundaries of the elongated grain structure gives a further hint of a strong anisotropy in the fracture properties of a heavily deformed tungsten wire. Observed features of a ductile as well as brittle fracture modes are very similar to the ones already reported for heavily deformed tungsten wires $[22,27,37]$. 


\section{a) side view}
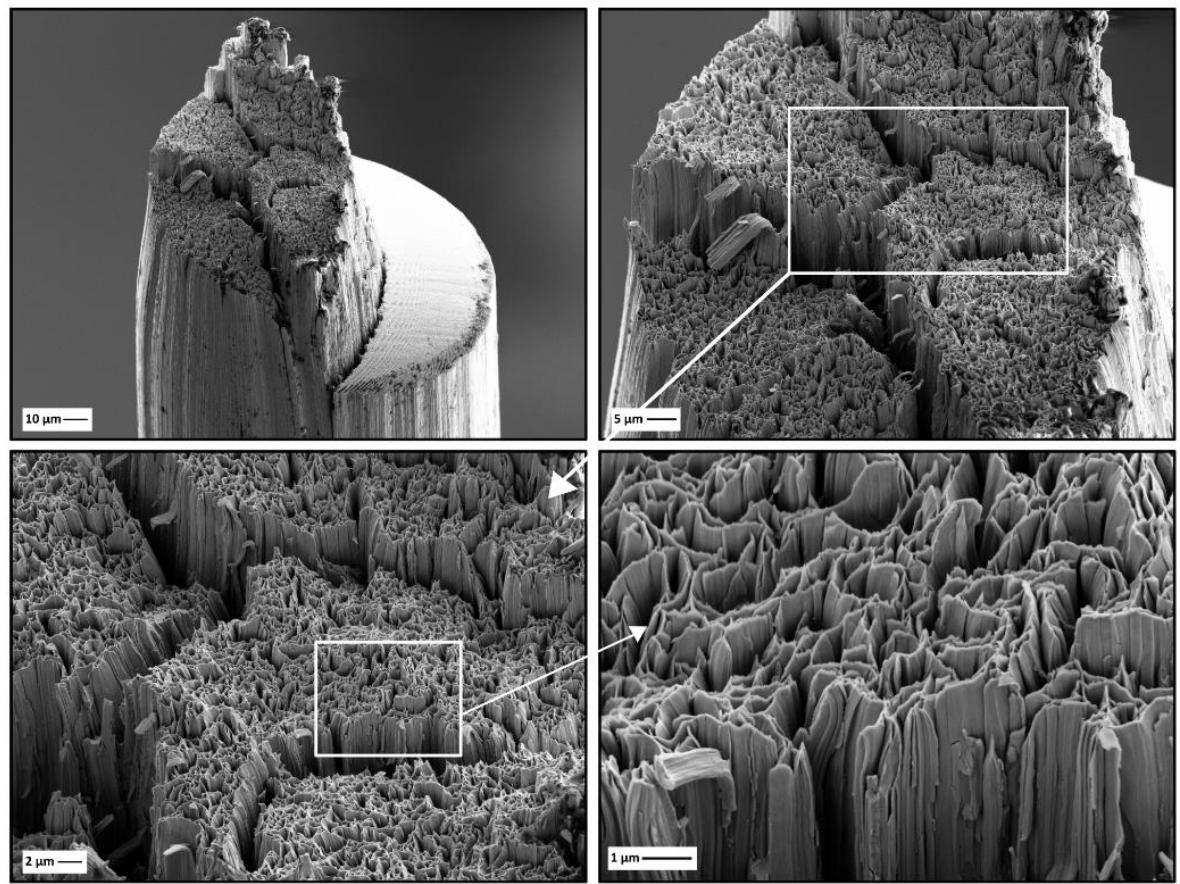

\section{b) top view}
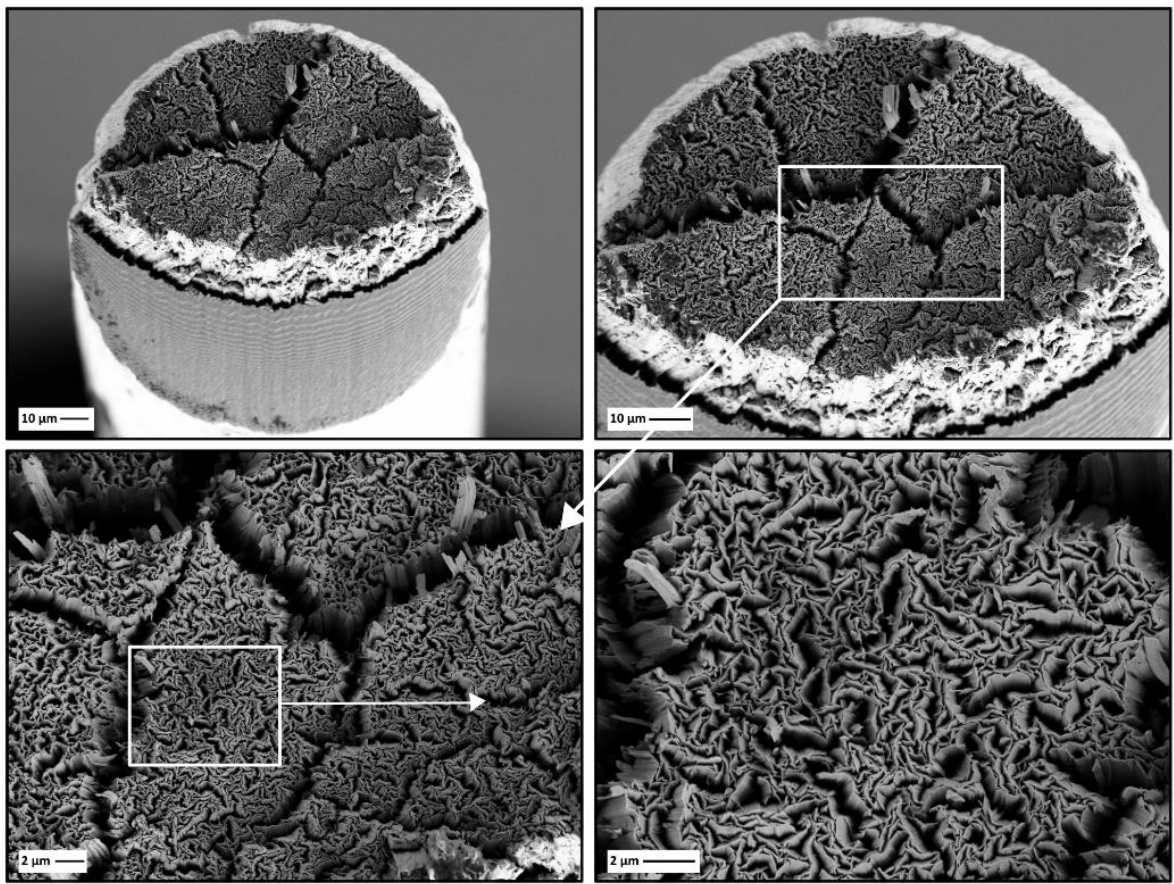

Figure 7. Scanning electron micrographs of a K-doped tungsten wire showing a typical ductile, knifeedge necking dominated fracture mode. Fracture surfaces are studied in a) a side view and b) a top view of the wire in respect to a laser notch. The most characteristic features of the fracture process are shown in the magnified images. 


\subsubsection{Annealed wires}

Fracture surfaces of the wires heat treated at the lower annealing temperature of $1300{ }^{\circ} \mathrm{C}$ for $1 \mathrm{~h}$ are shown in Figure 8. A tremendous difference in the micromechanisms controlling the fracture process can be observed when comparing pure (Figure 8a) and K-doped tungsten wires (Figure 8b). The failure mode of the undoped wire is characterized as a brittle, mixed one being composed of both cleavage and intergranular fracture. The most distinctive feature in this case is the absence of the crack deflection, with the fracture surface being mostly flat in respect to the wire axis. Thus, for this material state the crack path does not deviate from its designated mode I propagation direction. Annealed K-doped wire has a very similar failure appearance as in the as-received state, with the fracture surface including longitudinal cracks and knife-edge necking of the individual grains. In addition, small colonies of brittle grains can be observed (shown in the magnified fractographs in Figure 8b) with the cleavage surfaces roughly perpendicular to the longitudinal direction. However, as these areas are rather small and the knife-edge ruptures of individual fibres dominate over the fracture surface, the occurring failure mode can be considered as predominately a ductile one.

Influence of even higher heat treatments $\left(1600{ }^{\circ} \mathrm{C}\right.$ for $\left.1 \mathrm{~h}\right)$ on the resulting fracture morphologies can be seen in Figure 9, where once again comparison is made between the two types of the investigated materials. Pure $W$ shows a very similar appearance of mixed, brittle fracture as the samples annealed at $1300{ }^{\circ} \mathrm{C}$ : besides the cleavage planes with typical river lines, brittle intergranular grain boundary fractures are also occurring in between, as shown in the magnified fractographs in Figure 9a. The intergranular failure mode seems to dominate at the edge region of the wire which can be related to the heterogeneity of the stress state across the diameter $[43,44]$, occurring as a direct consequence of the drawing process. Such a correlation of the radial position and the resulting failure mode was anticipated from the observations of the localized variations in crystallographic orientation and the texture analyses, which were conducted in the first part of the publication [29]. Furthermore, the crack propagation direction remains in the same plane of the initial pre-crack with a decrease of the overall roughness of the fracture surface.

Once annealed at $1600^{\circ} \mathrm{C}$, the $\mathrm{K}$-doped tungsten wire shows a more noticeable variation of the micromechanisms taking place during the fracture process, as shown in Figure 9b. In this case, an increase in the area of the cleaved grains is observed, which can be associated with the observed decrease in fracture toughness. Magnified fractographs reveal that the cleaved planes are also roughly perpendicular in respect to the wire axis, with small longitudinal cracks occurring between the convoluted colonies of grains. Nevertheless, regardless of the existence of the brittle 
phase, the presence of the extensive necking of the wire diameter accompanied by a wide range of the knife-edge fractured individual grains underlines the remarkable fracture properties of a doped wire upon annealing.

a) pure $\mathbf{W}$

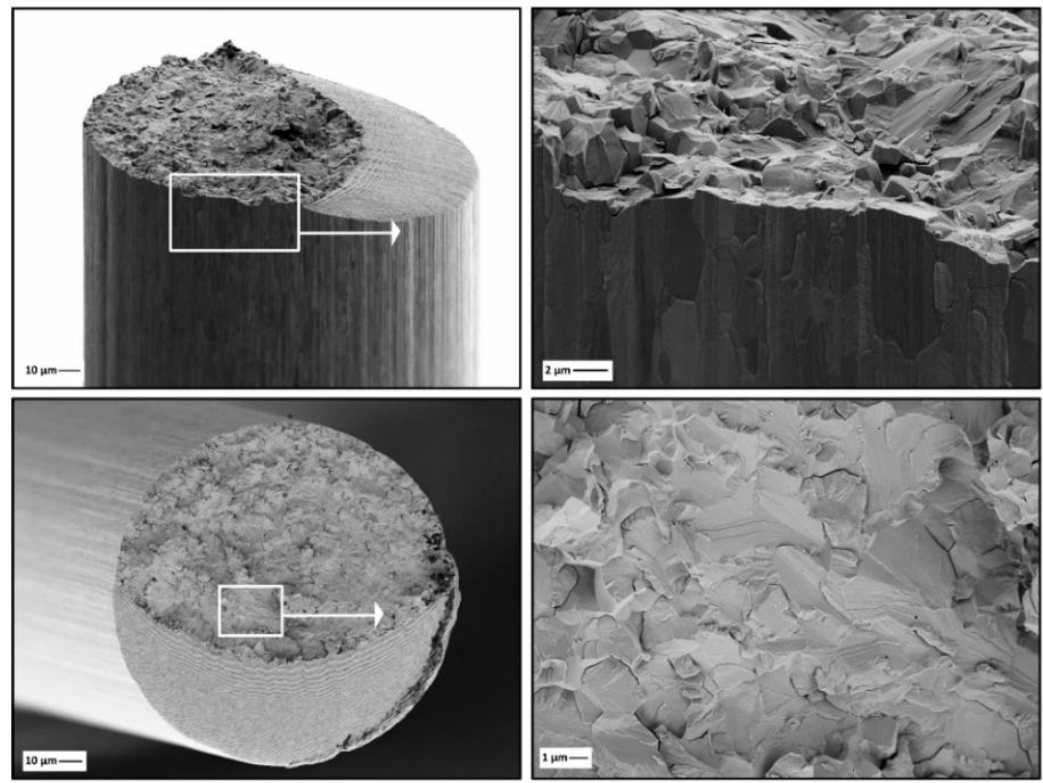

b) $\mathrm{K}$ doped $\mathrm{W}$

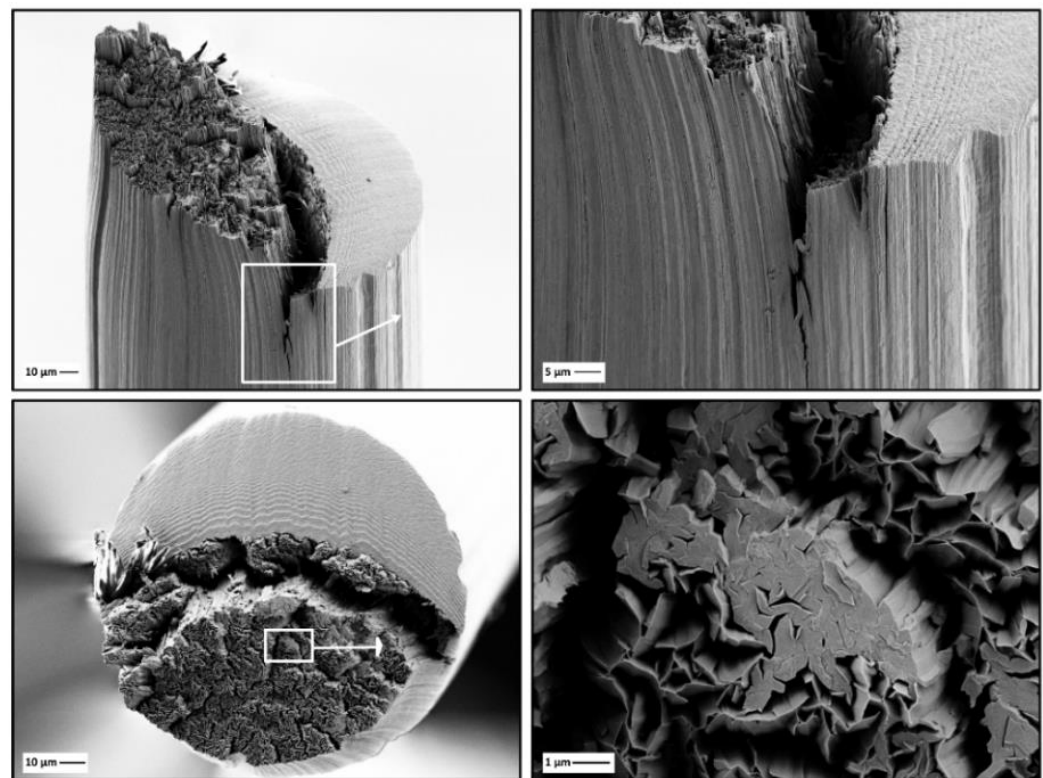

Figure 8. Scanning electron micrographs of tungsten wires annealed at $1300^{\circ} \mathrm{C}$ for $1 \mathrm{~h}$. A comparison is made between a) pure $W$ wire showing mixed, brittle failure mode consisting of both cleavage and intergranular fracture and b) $K$-doped $W$ wire showing predominately a typical ductile, knife-edge necking dominated fracture mode. 


\section{a) pure W}
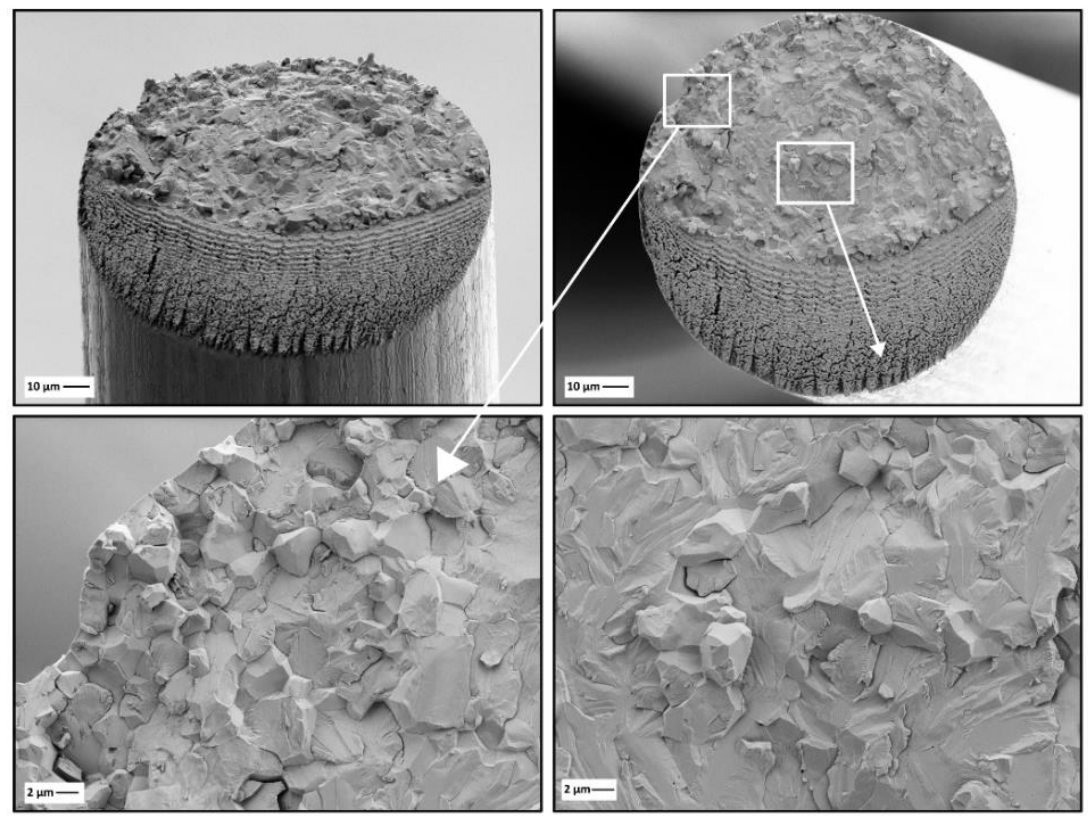

b) $\mathrm{K}$ doped $\mathrm{W}$
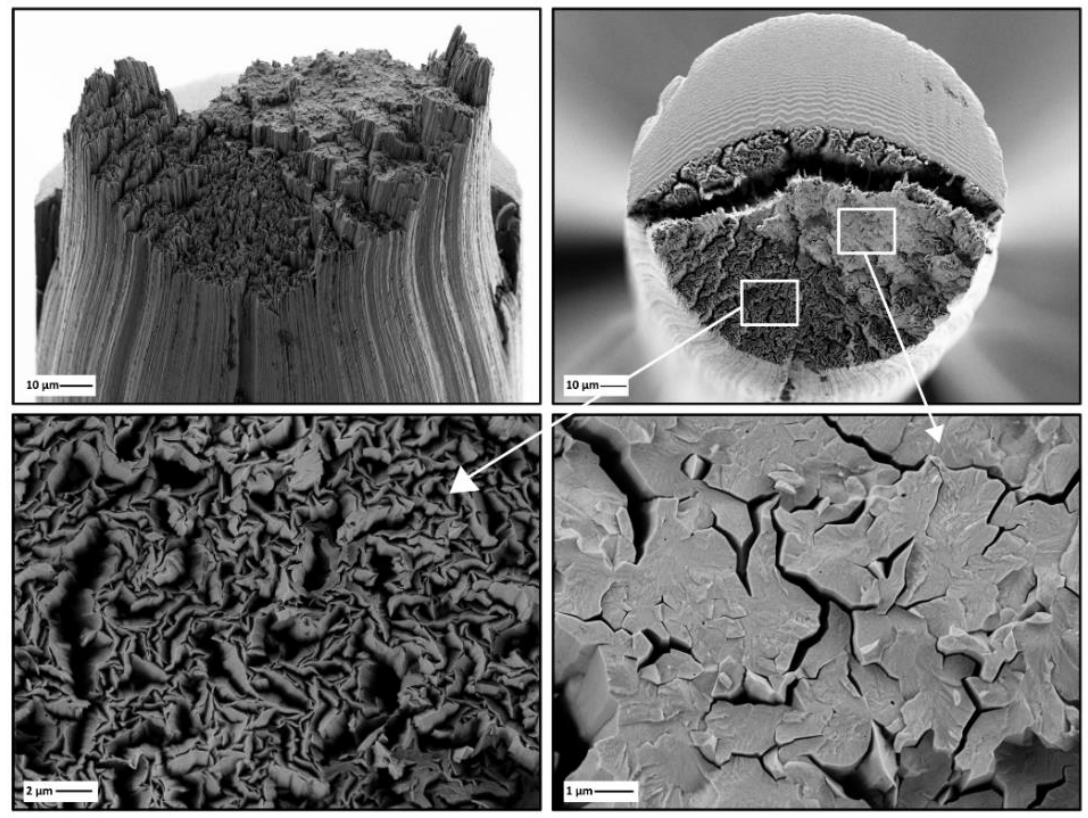

Figure 9. Scanning electron micrographs of tungsten wires annealed at $1600^{\circ} \mathrm{C}$ for $1 \mathrm{~h}$. A comparison is made between a) pure $W$ wire showing mixed, brittle failure mode consisting of both the cleavage and intergranular fracture (which is a dominant mode in the edge region) and b) K-doped $W$ wire showing a mixed fracture mode consisting of a typical ductile, knife-edge necking and cleavage with facets roughly perpendicular to the wire axis. 
A strong influence of fibrous, elongated grain structure with ultrafine size is clearly seen in a very ductile appearance of the respective fracture surfaces. Modifications of the initial grain structure by different heat treatments are also translated to the occurring failure mode in the case of heavily drawn tungsten wires. Thus, it is possible to find a correlation between the thermal history and micromechanisms controlling the fracture process, which is very important when discussing the beneficial influence of potassium doping. In the case of pure tungsten, annealing already at $1300{ }^{\circ} \mathrm{C}$ leads to a complete loss of elongated microstructure and a formation of large, equiaxed grains, which further increase in size by annealing at higher temperatures (Figure 2).

The influence of the thermal history is seen through a tremendous decrease in fracture toughness accompanied with a major change of the failure mode, which mostly can be related to the increased number of transverse grain boundaries. In the initial state of the wire, the weakness of the longitudinal grain boundaries is clearly seen through the occurrence of a strong crack deflection and the longitudinal cracking, while the transverse boundaries are widely separated and most likely not a preferred crack path. However, elevated thermal exposures above the recrystallization temperature can cause the formation of transverse boundaries through polygonization and by movement of a small section of the longitudinal boundaries [45]. Due to the overall changes in the grain size and shape of a pure W wire, instead of having transverse and longitudinal boundaries at approximately right angles to each other, the boundaries after annealing intersect at a variety of angles. As a result, a crack can more easily propagate from one grain boundary facet to another without deviating from the initial crack propagating direction leading to the intergranular appearance of the fracture surface. In some areas grains are cut through, resulting in characteristic river patterns of cleavage fracture.

In contrast to this, the K-doped wire shows remarkable fracture behaviour even after the heat treatments, which is ascribed to the preservation of the fibrous, elongated microstructure and is seen through predominately knife-edge fracture mode. Investigated heat treatments and annealing temperatures of $1300{ }^{\circ} \mathrm{C}$ to 1600 ${ }^{\circ} \mathrm{C}$ lead to a small degree of broadening of the fibres, which is related to an increase in the amount of transverse grain boundaries. If there are more boundaries of this type in the same plane, the probability of providing a nucleation site for cleavage rises, resulting in a reduced fracture toughness and larger amount of cleaved grains in the fracture surface. However, more substantial microstructural changes are prevented by finely dispersed rows of ultrafine sized potassium bubbles which act as pinning sites and can be seen in Figure 10. In such a way, the grain boundary migration is restricted resulting in a sluggish microstructural coarsening and a shift of the recrystallization to even higher temperatures than in the case of pure tungsten. 

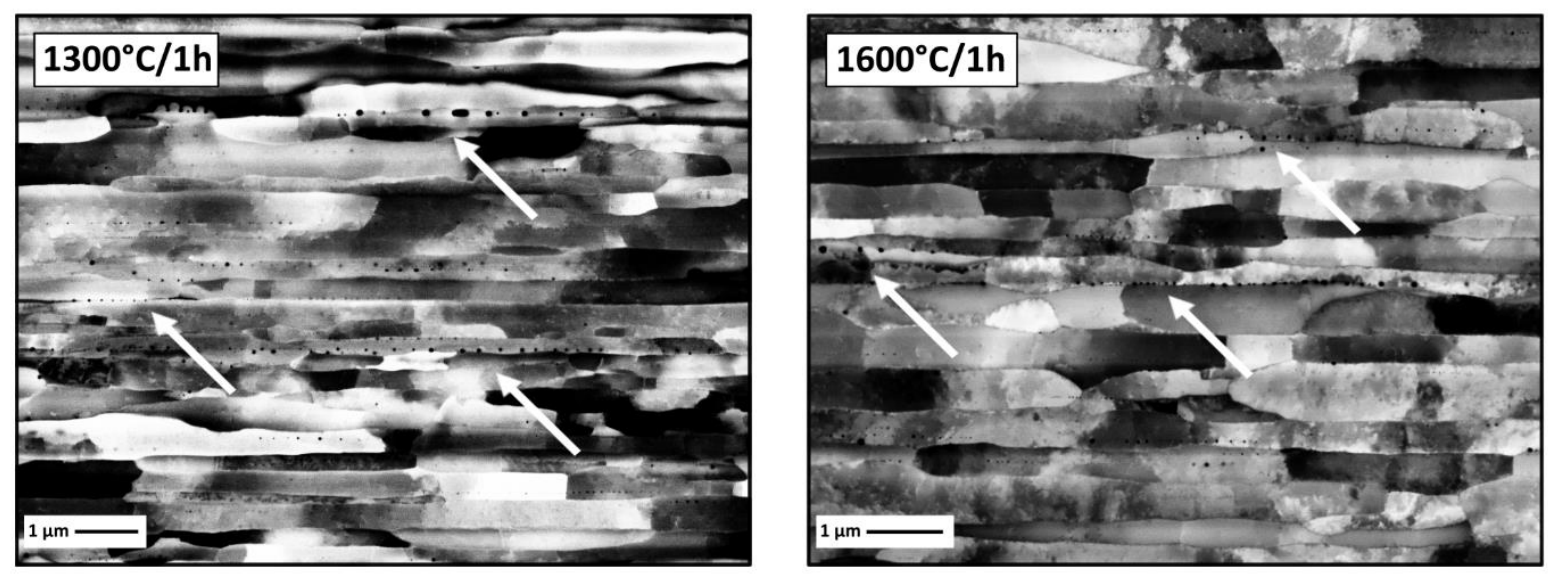

Figure 10. Scanning electron micrographs of the annealed, K-doped tungsten wires showing finely distributed rows of potassium bubbles which act as pinning sites and thus prevent grain boundary migration. The images are taken across the longitudinal sections in the BSE mode, while the dopants are indicated with white arrows.

\subsection{True vs. apparent fracture toughness}

Taking into account different criteria of underestimation of fracture toughness discussed in chapter 3.2.1., the evaluated critical stress intensity $\mathrm{K}$ can only be considered as an apparent crack resistance of the investigated wires. The biggest deviation from the valid $\mathrm{K}_{\mathrm{IC}}$ values, comes from the discrepancy between the designated mode I loading conditions and nearly immediate deflection of the crack propagation direction by $90^{\circ}$. Thus, the measured toughness and the extend of necking is influenced by a plastic limit load. In contrast to this, the experiments performed on the annealed pure tungsten wires deliver a valid $\mathrm{K}_{\mathrm{IC}}$ according to the ASTM 399 standard [46], as the crack does not deviate and can easily propagate in the designated direction. This is true for both heat treatments of $1300{ }^{\circ} \mathrm{C} / 1 \mathrm{~h}$ and $1600{ }^{\circ} \mathrm{C} / 1 \mathrm{~h}$, yielding fracture toughness of $(9.7 \pm 1.7) \mathrm{MPa} \cdot \mathrm{m}^{1 / 2}$ and $(7.6 \pm 1.1)$ $\mathrm{MPa} \cdot \mathrm{m}^{1 / 2}$, respectively. These results, highlighted in Table 1 , can be considered as a valid lower limit of fracture toughness, keeping in mind approximations regarding the definition of a crack front. In all the other samples, where a pronounced crack deflection takes place followed by a brittle cleavage or a knife edge ductile failure mode, it can be assumed that the true fracture toughness is significantly higher than 
the calculated $\mathrm{K}$ values. The question is by which order of the magnitude are the obtained results underestimated in comparison to material's true crack resistance?

A convenient method of measuring fracture toughness of ductile materials in the elastic-plastic regime is by determining crack tip opening displacement (CTOD), which measures a degree of blunting of a crack tip before the crack propagation takes place [47]. CTOD parameter is related to a more geometry independent toughness $\mathrm{K}_{\text {СтоD }}$ and is usually determined by stereophotogrammetric reconstruction of fracture surfaces, where a local plastic deformation is extracted from the 3D microscopic topography [48,49]. Additional fractographic analyses of samples fracturing in a ductile manner reveal small areas of a fibrous knife-edge necking over a very small distance as a first subcritical crack growth in mode I, followed by a strong deflection of a crack and occurrence of vertical walls of grains (Figure 11). Shown example is of a K-doped wire with a measured $\mathrm{K}$ value of 44.5 $\mathrm{MPa} \cdot \mathrm{m}^{1 / 2}$. A rough estimation of a CTOD parameter can be extracted from the dimension of this ductile area before the propagation step occurs, giving an approximate value of about $9 \mu \mathrm{m}$. Employing the expression between CTOD and

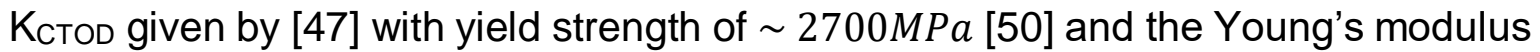
of $\sim 400 \mathrm{GPa}$ [6], an estimated fracture toughness of about $98.5 \mathrm{MPa} \cdot \mathrm{m}^{1 / 2}$ is obtained. Therefore, experimental results yield an underestimation of a true fracture toughness of tungsten wires at least by a factor of two. Similar features in failure mode and estimations of $\mathrm{K}$ are seen for pure tungsten, as well as the annealed $\mathrm{K}$ doped wire, where a dominant micromechanism of fracture is ductile, fibrous mode having some isolated cleavage facets indicating a locally brittle fracture.
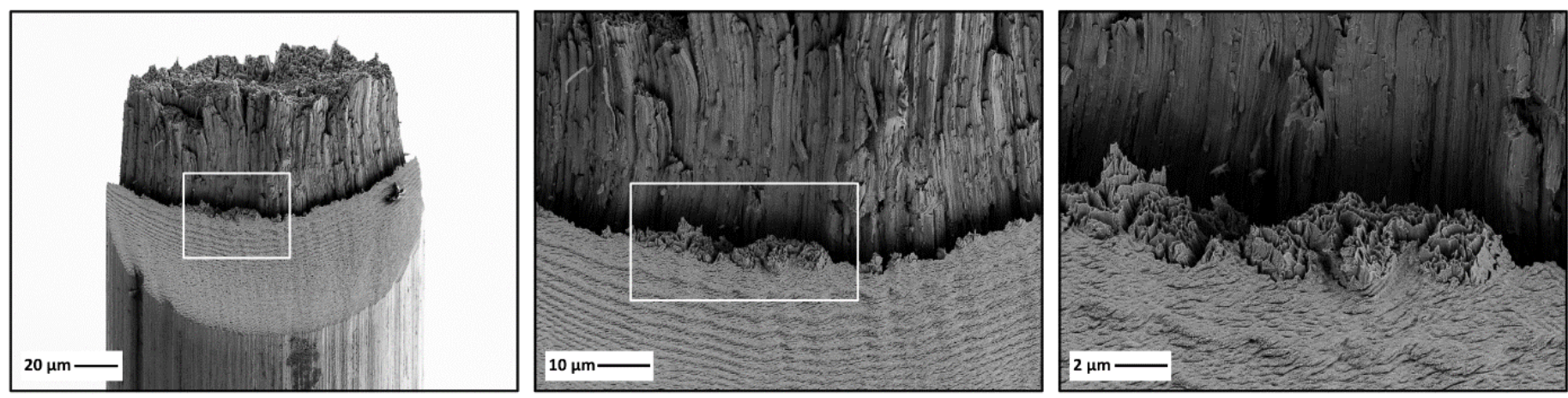

Figure 11. Side view of a scanning electron micrographs of a K-doped tungsten wire showing a typical ductile, knife-edge necking dominated fracture mode. A small ductile area, occurring before the crack deflects by $90^{\circ}$, is used in approximating a CTOD parameter and estimating a true fracture toughness. 


\section{Conclusions}

The main scope of the study was the room temperature fracture mechanical assessment of pure and potassium doped tungsten wires with a diameter of $150 \mu \mathrm{m}$. The investigation was predominantly focused on the evolution of the fracture mechanisms in respect to annealing, with selected heat treatment temperatures being $1300{ }^{\circ} \mathrm{C}$ and $1600{ }^{\circ} \mathrm{C}$. In such a way, a relationship between the microstructural features, annealing phenomena and resulting fracture properties were established. The main findings can be summarized as following:

- The fracture properties of both types of wires in the as-received state are very similar. The occurrence of either brittle or ductile materials response in a test is observed, which is related to either lower or higher obtained values of fracture toughness, respectively. The existence of a scatter of measured $\mathrm{K}$ data is an indication that the DBTT is around RT.

- With an increase in annealing temperature pure tungsten wire shows a significant reduction in toughness as a result of embrittlement by annealing. The influence of heat treatments is significantly milder in the case of K-doped material, as the decrease in toughness, even after annealing at $1600^{\circ} \mathrm{C}$ is not as pronounced.

- Comprehensive SEM investigation of the fracture surfaces reveals the following main characteristics:

$\checkmark$ A very prominent crack deflection by about $90^{\circ}$ at the initial stage of the fracture process. Such a distinctive feature, occurring in the majority of tested samples, appears as a consequence of the elongated microstructure and is a strong indication of a very prominent anisotropy in fracture toughness.

$\checkmark$ Predominant micromechanisms of the as-received samples failing in a brittle manner is transcrystalline cleavage across the diameter of the wire, accompanied with the absence of necking.

$\checkmark$ Fracture appearance of the as-received samples failing in a ductile manner is designated as knife-edge failure mode and characterised by distinct necking of the entire wire, longitudinal delaminations and necking of the grains to almost $100 \%$ reduction in area.

$\checkmark$ A tremendous change of the failure mode is perceived for pure tungsten wire after annealing. The most noticeable feature is the absence of crack deflection with the resulting fracture surface being 
mostly flat in respect to the wire axis. The failure mode is a mixed brittle one, being composed of both cleavage and intergranular fracture.

$\checkmark$ Annealed doped tungsten wire has a very similar ductile fracture appearance as in the as-received state. Increase in annealing temperature, results with an increase in the amount of brittle, cleaved grains, which are roughly perpendicular to the drawing direction.

- An additional sharpening of the laser notch by a FIB cut does not have an influence on the resulting fracture process.

- Considering different criteria of underestimation, the evaluated fracture toughness can be regarded as an apparent crack resistance of the tungsten wire. The extent of underestimation can be estimated from the CTOD measurements, approximating that the true fracture toughness is higher by at least a factor of two.

The main conclusion of the work is that the underlying microstructure is the key parameter controlling the resulting fracture process. In the case of pure tungsten wires, the microstructural modifications induced by annealing are directly reflected in fractographic features and a tremendous variation of a failure mode is observed. Thus, the occurring embrittlement can be correlated to the loss of the fibrous, elongated grain structure. In contrast to that, addition of potassium as a doping element results in a restriction of the grain boundary migration and a sluggish microstructural coarsening, maintaining in such a way a ductile behaviour up to very high temperatures. Therefore, from a perspective of investigated fracture properties, the application of K-doped tungsten wires is strongly advised for a structural part of fusion reactors, as it is the case for $\mathrm{W}_{\mathrm{f}} / \mathrm{W}$ composites.

\section{Acknowledgments}

This work has been carried out within the framework of the EUROfusion, on Consortium and has received funding from the Euratom research and training programme 2014-2018 under grant agreement No 633053. The views and opinions expressed herein do not necessarily reflect those of the European Commission. 


\section{$\underline{\text { References }}$}

[1] H. Zohm, Assessment of DEMO challenges in technology and physics, Fusion Eng. Des. 88 (2013) 428-433. doi:10.1016/j.fusengdes.2013.01.001.

[2] D. Stork, P. Agostini, J.L. Boutard, D. Buckthorpe, E. Diegele, S.L. Dudarev, C. English, G. Federici, M.R. Gilbert, S. Gonzalez, A. Ibarra, C. Linsmeier, A. Li Puma, G. Marbach, P.F. Morris, L.W. Packer, B. Raj, M. Rieth, M.Q. Tran, D.J. Ward, S.J. Zinkle, Developing structural, high-heat flux and plasma facing materials for a near-term DEMO fusion power plant: The EU assessment, J. Nucl. Mater. 455 (2014) 277-291.

doi:10.1016/j.jnucmat.2014.06.014.

[3] C. Linsmeier, M. Rieth, J. Aktaa, T. Chikada, A. Hoffmann, J. Hoffmann, A. Houben, H. Kurishita, X. Jin, M. Li, A. Litnovsky, S. Matsuo, A. Von Müller, V. Nikolic, T. Palacios, R. Pippan, D. Qu, J. Reiser, J. Riesch, T. Shikama, R. Stieglitz, T. Weber, S. Wurster, J.-H. You, Z. Zhou, Development of advanced high heat flux and plasma-facing materials, 92007 (2017). doi:10.1088/1741-4326/aa6f71.

[4] M. Rieth, S.L. Dudarev, S.M. Gonzalez De Vicente, J. Aktaa, T. Ahlgren, S. Antusch, D.E.J. Armstrong, M. Balden, N. Baluc, M.F. Barthe, W.W. Basuki, M. Battabyal, C.S. Becquart, D. Blagoeva, H. Boldyryeva, J. Brinkmann, M. Celino, L. Ciupinski, J.B. Correia, A. De Backer, C. Domain, E. Gaganidze, C. García-Rosales, J. Gibson, M.R. Gilbert, S. Giusepponi, B. Gludovatz, H. Greuner, K. Heinola, T. Höschen, A. Hoffmann, N. Holstein, F. Koch, W. Krauss, H. Li, S. Lindig, J. Linke, C. Linsmeier, P. López-Ruiz, H. Maier, J. Matejicek, T.P. Mishra, M. Muhammed, A. Muñoz, M. Muzyk, K. Nordlund, D. Nguyen-Manh, J. Opschoor, N. Ordás, T. Palacios, G. Pintsuk, R. Pippan, J. Reiser, J. Riesch, S.G. Roberts, L. Romaner, M. Rosiński, M. Sanchez, W. Schulmeyer, H. Traxler, A. Ureña, J.G. Van Der Laan, L. Veleva, S. Wahlberg, M. Walter, T. Weber, T. Weitkamp, S. Wurster, M.A. Yar, J.H. You, A. Zivelonghi, Recent progress in research on tungsten materials for nuclear fusion applications in Europe, J. Nucl. Mater. 432 (2013) 482-500. doi:10.1016/j.jnucmat.2012.08.018.

[5] V. Philipps, Tungsten as material for plasma-facing components in fusion devices, J. Nucl. Mater. 415 (2011) S2-S9.

doi:10.1016/j.jnucmat.2011.01.110.

[6] E. Lassner, W.-D. Schubert, Tungsten - Properties, Chemistry, Technology of the Element, Alloys and Chemical Compounds, Kluwer Academic/Plenum Publishers, New York, 1999.

[7] V. Barabash, G. Federici, M. Rödig, L.L. Snead, C.H. Wu, Neutron irradiation 
effects on plasma facing materials, J. Nucl. Mater. 283-287 (2000) 138-146. doi:10.1016/S0022-3115(00)00203-8.

[8] G. Pintsuk, S. Antusch, T. Weingaertner, M. Wirtz, Recrystallization and composition dependent thermal fatigue response of different tungsten grades, Int. J. Refract. Met. Hard Mater. 72 (2018) 97-103. doi:10.1016/j.jijmhm.2017.11.039.

[9] Y. Yuan, J. Du, M. Wirtz, G.N. Luo, G.H. Lu, W. Liu, Surface damage and structure evolution of recrystallized tungsten exposed to ELM-like transient loads, Nucl. Fusion. 56 (2016). doi:10.1088/0029-5515/56/3/036021.

[10] P.L. Raffo, Yielding and Fracture in tungsten and tungsten rhenium alloys, J. Less-Common Met. (1969) 133 - 149.

[11] S. Wurster, B. Gludovatz, R. Pippan, High temperature fracture experiments on tungsten-rhenium alloys, Int. J. Refract. Met. Hard Mater. 28 (2010) 692697. doi:10.1016/j.jijmhm.2010.03.002.

[12] A. Luo, D.L. Jacobson, K.S. Shin, Solution softening mechanism of iridium and rhenium in tungsten at room temperature, Int. J. Refract. Met. Hard Mater. 10 (1991) 107-114. doi:10.1016/0263-4368(91)90028-M.

[13] Q. Wei, L.J. Kecskes, Effect of low-temperature rolling on the tensile behavior of commercially pure tungsten, Mater. Sci. Eng. A. 491 (2008) 6269. doi:10.1016/j.msea.2008.01.013.

[14] V. Nikolic, S. Wurster, D. Firneis, R. Pippan, Improved fracture behavior and microstructural characterization of thin tungsten foils, Nucl. Mater. Energy. 9 (2016) 181-188. doi:10.1016/j.nme.2016.06.003.

[15] R. Neu, J. Riesch, A. V. Müller, M. Balden, J.W. Coenen, H. Gietl, T. Höschen, M. Li, S. Wurster, J.H. You, Tungsten fibre-reinforced composites for advanced plasma facing components, Nucl. Mater. Energy. 12 (2017) 1308-1313. doi:10.1016/j.nme.2016.10.018.

[16] J. Riesch, T. Höschen, C. Linsmeier, S. Wurster, J.H. You, Enhanced toughness and stable crack propagation in a novel tungsten fibre-reinforced tungsten composite produced by chemical vapour infiltration, Phys. Scr. T159 (2014). doi:10.1088/0031-8949/2014/T159/014031.

[17] J. Riesch, M. Aumann, J.W. Coenen, H. Gietl, G. Holzner, T. Höschen, P. Huber, M. Li, C. Linsmeier, R. Neu, Chemically deposited tungsten fibrereinforced tungsten - The way to a mock-up for divertor applications, Nucl. Mater. Energy. 9 (2016) 75-83. doi:10.1016/j.nme.2016.03.005.

[18] B. Jasper, S. Schoenen, J. Du, T. Hoeschen, F. Koch, C. Linsmeier, R. Neu, J. Riesch, A. Terra, J.W. Coenen, Behavior of tungsten fiber-reinforced 
tungsten based on single fiber push-out study, Nucl. Mater. Energy. 9 (2016) 416-421. doi:10.1016/j.nme.2016.04.010.

[19] P. Schade, Materials 100 years of doped tungsten wire, Int. J. Refract. Met. Hard Mater. 28 (2010) 648-660. doi:10.1016/j.jijmhm.2010.05.003.

[20] C.L. Briant, B.P. Bewlay, The Coolidge Process for Making Tungsten Ductile: The Foundation of Incandescent Lighting, MRS Bull. 20 (1995) 67-73. doi:10.1557/S0883769400045164.

[21] E. Pink, L. Bartha, The metallurgy of doped/non-sag tungsten, Elsevier Science Publishers, 1989.

[22] P. Schade, Wire drawing failures and tungsten fracture phenomena, Int. J. Refract. Met. Hard Mater. 24 (2006) 332-337.

doi:10.1016/j.jjmhm.2005.09.003.

[23] O. Horacsek, Properties and failure modes of incandescent tungsten filaments, IEE Proc. A (Physical Sci. Meas. Instrumentation, Manag. Educ. Rev. 127 (1980) 134-141. doi:10.1049/ip-a-1.1980.0023.

[24] D. Lee, Fracture of drawn tungsten wires, Metall. Trans. A. 6 (1975) $2083-$ 2088. doi:10.1007/BF03161834.

[25] J.L. Walter, C.L. Briant, E.F. Koch, Splitting of Tungsten Wire in the KnifeEdge Compression Test., Metall. Trans. A, Phys. Metall. Mater. Sci. 13 A (1982) 1501-1510. doi:10.1007/BF02642889.

[26] A.W. Funkenbusch, F. Bacon, D. Lee, The influence of microstructure on fracture of drawn tungsten wire, Metall. Trans. A. 10 (1979) 1085-1091. doi:10.1007/BF02811654.

[27] S. Leber, J. Tavernelli, D.D. White, R.F. Hehemann, Fracture modes in tungsten wire, J. Less-Common Met. 48 (1976) 119-133. doi:10.1016/00225088(76)90238-1.

[28] R.H. Forster, A. Gilbert, The effect of grain structure on the fracture of recrystallized tungsten wire, J. Less-Common Met. 20 (1970) 315-325.

[29] V. Nikolić, J. Riesch, R. Pippan, The effect of heat treatments on pure and potassium doped drawn tungsten wires: Part I - Microstructural characterization, Mater. Sci. Eng. A. (2018) submitted.

[30] M.J. Pfeifenberger, M. Mangang, S. Wurster, J. Reiser, A. Hohenwarter, W. Pfleging, D. Kiener, R. Pippan, The use of femtosecond laser ablation as a novel tool for rapid micro-mechanical sample preparation, Mater. Des. 121 (2017) 109-118. doi:10.1016/j.matdes.2017.02.012.

[31] B.N. Chichkov, C. Momma, S. Nolte, F. von Alvensleben, A. Tünnermann, 
Femtosecond, picosecond and nanosecond laser ablation of solids, Appl. Phys. A Mater. Sci. Process. 63 (1996) 109-115. doi:10.1007/s003390050359.

[32] A. Hohenwarter, B. Völker, M.W. Kapp, Y. Li, S. Goto, D. Raabe, R. Pippan, Ultra-strong and damage tolerant metallic bulk materials: A lesson from nanostructured pearlitic steel wires, Sci. Rep. 6 (2016) 1-10. doi:10.1038/srep33228.

[33] J. Toribio, N. Álvarez, B. González, J.C. Matos, A critical review of stress intensity factor solutions for surface cracks in round bars subjected to tension loading, Eng. Fail. Anal. 16 (2009) 794-809. doi:10.1016/j.engfailanal.2008.06.023.

[34] M.R. Ripoll, J. Očenášek, Microstructure and texture evolution during the drawing of tungsten wires, Eng. Fract. Mech. 76 (2009) 1485-1499. doi:10.1016/j.engfracmech.2009.02.012.

[35] W.F.J. Hosford, Microstructural changes during deformation of [011] fiber textured metals, Trans. Metall. Soc. AIME. 230 (1964) 12-15.

[36] D.B. Snow, The recrystallization of commercially pure and doped tungsten wire drawn to high strain, Metall. Trans. A. 10 (1979) 815-821. doi:10.1007/BF02658299.

[37] P. Zhao, J. Riesch, T. Höschen, J. Almanstötter, M. Balden, J.W. Coenen, R. Himml, W. Pantleon, U. von Toussaint, R. Neu, Microstructure, mechanical behaviour and fracture of pure tungsten wire after different heat treatments, Int. J. Refract. Met. Hard Mater. 68 (2017) 29-40. doi:10.1016/j.jirmhm.2017.06.001.

[38] C.A. Valiente, Criterios de fractura para alambres, 1980.

[39] T. Palacios, J.Y. Pastor, Influence of the notch root radius on the fracture toughness of brittle metals: Nanostructure tungsten alloy, a case study, RMHM. 52 (2015) 44-49. doi:10.1016/j.jrmhm.2015.05.012.

[40] C. Bonnekoh, A. Hoffmann, J. Reiser, The brittle-to-ductile transition in cold rolled tungsten: On the decrease of the brittle-to-ductile transition by $600 \mathrm{~K}$ to - $65^{\circ} \mathrm{C}$, Int. J. Refract. Met. Hard Mater. 71 (2018) 181-189. doi:10.1016/j.jjrmhm.2017.11.017.

[41] V. Nikolić, S. Wurster, D. Firneis, R. Pippan, Fracture toughness evaluation of UFG tungsten foil, Int. J. Refract. Met. Hard Mater. 76 (2018) 214-225. doi:10.1016/j.jjmhm.2018.06.008.

[42] J. Toribio, F.J. Ayaso, Anisotropic fracture behaviour of cold drawn steel : a materials science approach, Mater. Sci. Eng. 343 (2003) 265-272. 
doi:10.1016/S0921-5093(02)00364-7.

[43] M.R. Ripoll, S.M. Weygand, H. Riedel, Reduction of tensile residual stresses during the drawing process of tungsten wires, Mater. Sci. Eng. A. 527 (2010) 3064-3072. doi:10.1016/j.msea.2010.01.079.

[44] J.G. Sevillano, D. González, Heterogeneous Deformation and Internal Stresses Developed in BCC Wires by Axisymmetric Elongation, 550 (2007) 75-84. doi:10.4028/www.scientific.net/MSF.550.75.

[45] C.L. Briant, Cleavage of tungsten rod, Mater. Sci. Technol. 7 (1991) 739 745. doi:10.1179/026708391790184889.

[46] ASTM E399-90, Standard test method for plane-strain fracture toughness of metallic materials., (1997).

[47] T.L.Anderson, Fracture mechanics : fundamentals and applications, 2004.

[48] J. Stampfl, S. Scherer, M. Berchthaler, M. Gruber, O. Kolednik, Determination of the fracture toughness by automatic image processing, Int. J. Fract. 78 (1996) 35-44. doi:10.1007/BF00018499.

[49] J. Stampfl, S. Scherer, M. Gruber, O. Kolednik, Reconstruction of surface topographies by scanning electron microscopy for application in fracture research, Appl. Phys. A Mater. Sci. Process. 63 (1996) 341-346. doi:10.1007/BF01567324.

[50] J. Riesch, Y. Han, J. Almanstötter, J.W. Coenen, T. Höschen, B. Jasper, P. Zhao, C. Linsmeier, R. Neu, Development of tungsten fibre-reinforced tungsten composites towards their use in DEMO - Potassium doped tungsten wire, Phys. Scr. 2016 (2016) 14006. doi:10.1088/0031-8949/T167/1/014006. 